OPEN ACCESS

Edited by:

Akio Adachi,

Kansai Medical University, Japan

Reviewed by:

Duncan Wilson,

Albert Einstein College of Medicine,

United States

Russell Diefenbach,

Macquarie University, Australia Joel D. Baines,

Louisiana State University, United States

*Correspondence: Anchun Cheng

chenganchun@vip.163.com Mingshu Wang

mshwang@163.com

tThese authors have contributed equally to this work and share first

authorship

Specialty section: This article was submitted to Virology,

a section of the journa

Frontiers in Microbiology

Received: 19 May 2020

Accepted: 21 July 2020

Published: 07 August 2020

Citation:

Wu L, Cheng A, Wang M, Jia $R$, Yang $Q$, Wu Y, Zhu D, Zhao X, Chen S, Liu M, Zhang S, Ou X, Mao S, Gao Q, Sun D, Wen X, Liu Y, Yu Y, Zhang L, Tian B, Pan $L$ and Chen X (2020) Alphaherpesvirus Major Tegument Protein VP22: Its

Precise Function in the Viral Life Cycle. Front. Microbiol. 11:1908. doi: 10.3389/fmicb.2020.01908

\section{Alphaherpesvirus Major Tegument Protein VP22: Its Precise Function in the Viral Life Cycle}

\author{
Liping Wu ${ }^{1,2,3+}$, Anchun Cheng ${ }^{1,2,3 *}$, Mingshu Wang ${ }^{1,2,3 *}$, Renyong Jia ${ }^{1,2,3}$, Qiao Yang ${ }^{1,2,3}$,

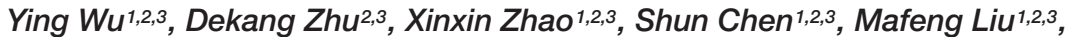 \\ Shaqiu Zhang 1,2,3, Xuming Ou, 1,2,3, Sai Mao 1,2,3, Qun Gao 1,2,3, Di Sun ${ }^{1,2,3}$, Xinjian Wen ${ }^{1,2,3}$,

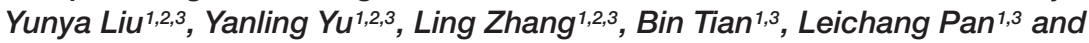 \\ Xiaoyue Chen ${ }^{1,2,3}$
}

${ }^{1}$ Institute of Preventive Veterinary Medicine, Sichuan Agricultural University, Chengdu, China, ${ }^{2}$ Key Laboratory of Animal Disease and Human Health of Sichuan Province, Sichuan Agricultural University, Chengdu, China, ${ }^{3}$ Avian Disease Research Center, College of Veterinary Medicine, Sichuan Agricultural University, Chengdu, China

Alphaherpesviruses are zoonotic pathogens that can cause a variety of diseases in humans and animals and severely damage health. Alphaherpesvirus infection is a slow and orderly process that can lie dormant for the lifetime of the host but may be reactivated when the immune system is compromised. All alphaherpesviruses feature a protein layer called the tegument that lies between the capsid and the envelope. Virus protein (VP) 22 is one of the most highly expressed tegument proteins; there are more than 2,000 copies of this protein in each viral particle. VP22 can interact with viral proteins, cellular proteins, and chromatin, and these interactions play important roles. This review summarizes the latest literature and discusses the roles of VP22 in viral gene transcription, protein synthesis, virion assembly, and viral cell-to-cell spread with the purpose of enhancing understanding of the life cycle of herpesviruses and other pathogens in host cells. The molecular interaction information herein provides important reference data.

Keywords: alphaherpesvirus, tegument protein VP22, secondary envelopment, viral replication, immune evasion

\section{INTRODUCTION}

The members of Herpesviridae are double-stranded DNA (dsDNA) viruses with a tegument structure (Crump, 2018). Currently, there are more than 120 known types of herpesviruses. In 1981, the International Commission on Taxonomy of Viruses (ICTV) recommended that the herpesvirus family be divided into three subfamilies (Alphaherpesvirinae, Betaherpesvirinae, and Gammaherpesvirinae), each subfamily of which has many unclassified viruses. Additionally, many herpesviruses have not yet been classified into a specific subfamily (Roizman et al., 1981). The herpes simplex virus types 1 and 2 (HSV-1 and HSV-2, respectively), duck enteritis virus (DEV), varicella-zoster virus (VZV), bovine herpesvirus 1 (BoHV-1), Marek's disease virus (MDV), and pseudorabies virus (PRV) all belong to the Alphaherpesvinae subfamily. Human and murine cytomegalovirus (HCMV and MCMV, respectively) belong to the Betaherpesvirinae subfamily, while Epstein-Barr virus (EBV) and Kaposi's sarcoma-associated herpesvirus (KSHV) belong to the Gammaherpesvirinae subfamily (Foulon, 1992).

Viruses depend on host cells for proliferation, so viruses enter host cells through endocytosis and membrane fusion (Mercer et al., 2010). When a viral particle infects a cell, viral envelope 
glycoproteins mediate the fusion of the viral envelope and the cell membrane (Johnson and Baines, 2011). Subsequently, the viral nucleocapsid is released into the cytoplasm, and viral DNA migrates into the nucleus through the nuclear pore and begins to replicate, initiating transcription of the viral genome (Liashkovich et al., 2011). The capsid is assembled in the nucleus, and then the genome is packed into the preformed capsid (Heming et al., 2017). Next, primary envelopment and de-envelopment occurs through budding into the inner nuclear membrane and subsequent fusion with the outer nuclear membrane (Bigalke and Heldwein, 2016). During secondary envelopment a subset of tegument proteins are incorporated into the viral particle (Kramer and Enquist, 2013). Virions are assembled in the lumena of large cytoplasmic vesicles that are transported to the cell periphery, where they fuse with the plasma membrane and release viral particles from the cell (Crump, 2018) (Figure 1).

Herpesvirus particles are approximately spherical, with sizes varying from 120 to $300 \mathrm{~nm}$, and they are mainly composed of four parts from outside to inside: the envelope, tegument, capsid, and DNA genome core (Dargan, 1986; Roizman and Sears, 1996; Xie et al., 2019). The linear dsDNA genome is covered with an icosahedral capsid. The layer of protein between the capsid and outer envelope, collectively termed the tegument, is unique to herpesvirus (Metrick et al., 2020). Twenty-six tegument proteins have been found in HSV-1 (Loret et al., 2008; Kelly et al., 2009; Kukhanova et al., 2014). Tegument proteins play different roles during the viral life cycle, serving as structural components of the virion and functioning in transcriptional regulation, kinase activity, viral assembly, and immune evasion (Owen et al., 2015; Wang Y. et al., 2018; Tobler et al., 2019; Yang et al., 2019); for example, the Us3 protein can regulate the expression of viral genes, affect the immune function of the host, affect the spread of the virus between host cells, resist host cell apoptosis, and disrupt the host cell cytoskeleton (Van den Broeke et al., 2009; Chang et al., 2013; Grauwet et al., 2016).

The tegument protein VP22 possesses a protein transport function: it can carry a connecting fusion protein directly across the cell membrane into a cell without assistance, and the transported protein retains its original biological activity and function (Yu et al., 2012). In recent years, many studies have proposed the potential development and application of VP22 transduction in gene therapy (Ma et al., 2005; Nishi and Saigo, 2007; Yu X. et al., 2015; Yu et al., 2016), but the role of VP22 in the viral life cycle has not been fully elucidated. This article reviews the regulatory and structural role of alphaherpesvirus VP22 in the viral life cycle. According to the characteristics of VP22, we also propose some hypotheses and reflect on problems that remain to be solved.

\section{FEATURES OF VP22}

VP22 is found only in alphaherpesviruses and not in beta or gammaherpesviruses (Kelly et al., 2009). VP22 is encoded by a single gene, which is most commonly (but not always) designated UL49 in alphaherpesviruses (Wu et al., 2012). For example, the homologous protein of VP22 found in VZV is ORF9p, which is encoded by the ORF9 gene, and ORF9 is the most transcribed VZV gene during viral infection (Kennedy et al., 2005).

It is estimated that nearly 2,000 copies of VP22 are present within each virion, and despite its abundance, very little is known regarding the role of VP22 during viral infection (Heine et al., 1974). VP22 has a predicted molecular weight of $32 \mathrm{kDa}$, which is below the size limit for passive diffusion through nuclear pores (molecular weight of $40-45 \mathrm{kDa}$ ) (Elliott and Meredith, 1992; Leslie et al., 1996). Deletion of the UL49 gene impacts viral replication differently in different virus species. For MDV, EHV-1, and VZV, VP22 (or ORF9) is indispensable for viral replication in cultured cells (Dorange et al., 2002; Che et al., 2008; Okada et al., 2015), but for BoHV-1, PRV, and HSV, VP22 is dispensable for viral replication in cultured cells (Liang et al., 1995; del Rio et al., 2002; Duffy et al., 2006). However, the absence of VP22 weakens pathogenicity in natural hosts infected with BoHV-1 and in animal infection models of HSV, impairing viral replication and altering the protein composition of assembled virions in infected cells (Pomeranz and Blaho, 2000; Elliott et al., 2005).

\section{Viral Gene Encoding VP22}

The HSV-1 UL49 gene (NC_001806.2), which encodes VP22, is located in the UL48-UL49-UL49.5 region of the genome between the complementary sequences of the UL49.5 gene and the UL48 gene. The orientation of the UL49 gene is the same as the UL48 but opposite to the UL49.5 gene (Elliott and Meredith, 1992). The length of the UL49 gene differs somewhat among different alphaherpesviruses and generally ranges from 600 to 1,000 bp (Table 1).

According to the temporal sequence of gene expression during herpesvirus infection, viral genes are classified into immediate early (IE or $\alpha$ ) genes, early (E or $\beta$ ) genes, and late (L or $\gamma$ ) genes. The late proteins are involved in virus assembly, maturation, and egress. The late genes are further subdivided into $\gamma 1$ genes (which are partially dependent on viral DNA synthesis) and $\gamma 2$ genes (which are highly dependent on viral DNA synthesis) (Gruffat et al., 2016). The UL49 gene belongs to the $\gamma 1$ gene group and has been conserved during the evolution of alphaherpesviruses (Mouzakitis et al., 2005).

\section{Structure of VP22}

\section{Secondary Structure and Core Domain}

HSV-1 VP22 is capable of forming higher-order protein structures consisting of dimers or tetramers (Taddeo et al., 2007). Sequence analyses and secondary structure predictions have revealed that VP22 consists of a non-conserved N-terminal domain and a conserved C-terminal domain with clear secondary structures (O'Regan et al., 2007a). The VP22 core domains of VZV, PRV, MDV, and infectious laryngotracheitis virus (ILTV) all have conserved secondary structures (3 alpha helices and 1 beta chain) (Drozdetskiy et al., 2015). X-ray crystallography has revealed that VP22 of HSV-1 shares extensive structural similarity with ORF52 of Murid herpesvirus-68 (MHV-68) (subfamily Gammaherpesvirinae) (Song et al., 2005; Bortz et al., 2007). Comparisons of the sequences of VP22 in different viruses 


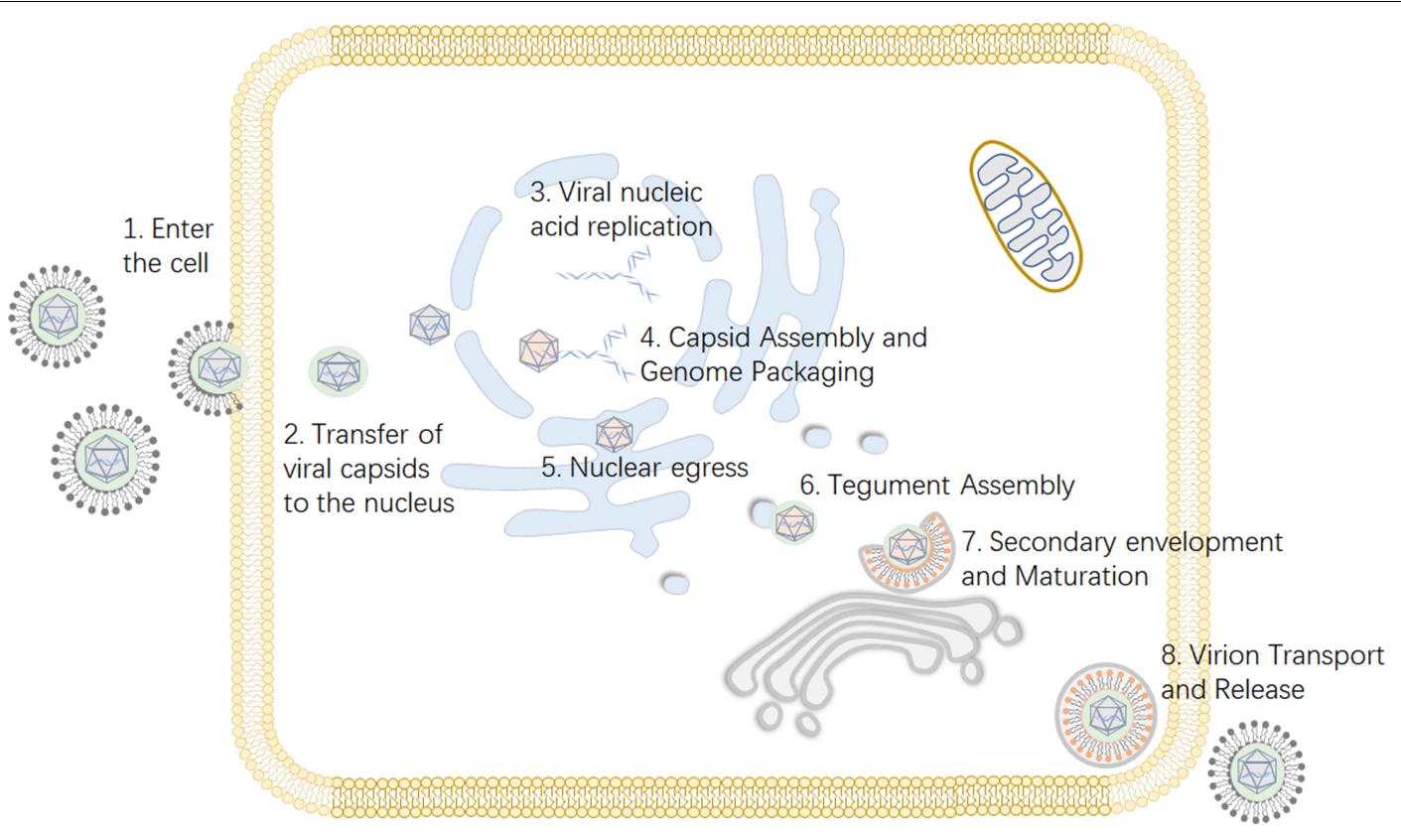

FIGURE 1 | Viral replication process of alphaherpesviruses. (1) The virus enters the host cell through membrane fusion. (2) Viral proteins transport the viral nucleocapsid to the nuclear pore. (3) After the viral DNA enters the nucleus, the viral genome is transcribed, and replication begins. (4) The viral capsid is formed and subsequently packaged with nucleic acid. (5) Nuclear export, also known as the primary envelopment and de-envelopment, occurs. (6) The assembly of tegument on capsids occurs predominantly in the cytoplasm following nuclear egress. (7) Secondary envelopment, which enables the virus to reach maturity, occurs. (8) The mature virus is released from the cell. Some inspiration for this figure was obtained from these previous articles (Zeev-Ben-Mordehai et al., 2014; You et al., 2017).

TABLE 1 | Features of alphaherpesvirus UL49 gene and homologs.

\begin{tabular}{|c|c|c|c|c|c|c|}
\hline Subfamily & Virus name & Abbreviation & Genomic sequence & Coding region & Coded protein & $\begin{array}{c}\text { Number of } \\
\text { bases }\end{array}$ \\
\hline \multirow[t]{15}{*}{ Alphaherpesvirinae } & Herpes simplex virus 1 & HSV-1 & NC_001806.2 & UL49 & VP22 & 906 \\
\hline & Herpes simplex virus 2 & HSV-2 & NC_001798.2 & UL49 & VP22 & 903 \\
\hline & Varicella-zoster virus & VZV & NC_001348.1 & ORF9 & VP22 & 909 \\
\hline & Saimiriine alphaherpesvirus 1 & $\mathrm{SaHV}-1$ & NC_014567.1 & UL49 & VP22 & 906 \\
\hline & Ateline alphaherpesvirus 1 & HVA1 & NC_034446.1 & UL49 & VP22 & 906 \\
\hline & Macacine alphaherpesvirus 1 & $\mathrm{CeHV}-1$ & NC_004812.1 & UL49 & VP22 & 870 \\
\hline & Psittacid alphaherpesvirus 1 & PsHV1 & NC_005264.1 & UL49 & VP22 & 855 \\
\hline & Duck enteritis virus & DEV & NC_013036.1 & UL49 & VP22 & 762 \\
\hline & Pseudorabies virus (Suid alphaherpesvirus 1) & PRV (SuHV-1) & NC_006151.1 & UL49 & VP22 & 750 \\
\hline & Gallid alphaherpesvirus 3 & MDV-2 & NC_002577.1 & UL49 & VP22 & 726 \\
\hline & Bovine alphaherpesvirus 1 & $\mathrm{BoHV}-1$ & NC_001847.1 & UL49 & VP22 & 777 \\
\hline & Felid alphaherpesvirus 1 & FeHV-1 & NC_013590.2 & UL49 & VP22 & 1038 \\
\hline & Testudinid herpesvirus 3 & TeHV-3 & NC_027916.2 & UL49 & VP22 & 639 \\
\hline & Meleagrid alphaherpesvirus 1 & MeHV-1 & NC_002641.1 & HVT057 & VP22 & 852 \\
\hline & Equid alphaherpesvirus 1 & EHV-1 & NC_001491.2 & ORF11 & VP22 & 915 \\
\hline
\end{tabular}

have indicated that the core domain length is 78-79 amino acids and is present in different positions of VP22 homologs (Trapp-Fragnet et al., 2019).

\section{Phosphorylated Protein}

VP22 is a posttranslationally modified phosphoprotein (Knopf and Kaerner, 1980; Hutchinson et al., 2002). The protein responsible for its phosphorylation varies in different herpesviruses. For example, the CKII and HSV-1 UL13 genes encode protein kinases that are responsible for the phosphorylation of VP22 (Elliott et al., 1996; Asai et al., 2007). In $\mathrm{VZV}$, a protein kinase encoded by the ORF47 gene is responsible (Riva et al., 2013). In addition, a protein kinase encoded by the US3 gene can weakly phosphorylate VP22 in BoHV-1 (Labiuk et al., 2010). However, VP22 exists in both phosphorylated and non-phosphorylated forms in infected cells, and only hypophosphorylated VP22 is incorporated into virions, and this dephosphorylation occurs independently of viral DNA 
replication or virion assembly (Pinard et al., 1987; Meredith et al., 1991; Geiss et al., 2001).

\section{Nuclear Localization Signal (NLS) and Nuclear Export Signal (NES)}

Although BoHV-1 VP22 is rich in basic amino acids, an analysis of the amino acid sequence of VP22 has shown that it does not have a classical nuclear localization signal (NLS) sequence; it accumulates in the nucleus of infected cells by an unknown mechanism (Zheng et al., 2005). Atypical nuclear localization signals refer to NLS without certain sequence characteristics. They are mainly present in proteins that can shuttle between the nucleus and cytoplasm. Transient transfection experiments with a fluorescently labeled fusion protein have further shown that the nuclear localization of VP22 is independent from that of other viral genes (Harms et al., 2000). In addition, many studies have reported that the C-terminus of BoHV-1 VP22 is essential for its nuclear localization (Ren et al., 2001; Zheng et al., 2005; Zhu et al., 2005). For example, one study has shown that amino acids 130-232 in BoHV-1 VP22 form the nuclear targeting sequence, which is capable of binding to histone $\mathrm{H} 4$, resulting in nuclear retention of VP22. In addition, a mitochondrial targeting sequence was present in the C-terminal 49 amino acids of VP22, overlapping the sequence required for nuclear targeting (Zhu et al., 2005). Other studies have demonstrated that the nuclear targeting sequence of BoHV-1 VP22 is located at amino acids 121-139, while amino acids 130-133 of VP22 form a functional non-classical NLS; amino acids 204-216 of VP22 have also been detected to form a nuclear export signal (NES) (Zheng et al., 2005). Further research has shown that amino acids 131-134 of BoHV-1 VP22 are not required for large-scale nuclear transport of proteins in later stages of infection but are essential for targeting of VP22 to discrete spot-like nuclear domains in the cytoplasm in the early stage (Lobanov et al., 2010). Overexpressed equine herpesvirus 1 (EHV-1) VP22 localizes to the cytoplasm and nucleus, and the phenomenon of VP22 transfer to the nucleus is more obvious under viral infection than under noninfection conditions; furthermore, amino acids 154-188 of EHV1 VP22 have been confirmed to be the NLS via truncation experiments (Okada et al., 2014).

\section{Functional Region}

HSV-1 VP22 associates with cellular membranes and enables transmembrane transport via a functional domain located between residues 120 and 225. The association of VP22 with cellular membranes may prove instrumental for the proper tegumentation and envelopment of virions. Interestingly, the primary structural alignment has revealed that the region of HSV-1 VP22 within amino acids 120-225 is highly conserved among VP22 homologs of herpesvirus, which raises the possibility that membrane association is a conserved attribute of VP22 (Brignati et al., 2003). In one study, the recombinant virus HSV-1 (RF177) was found to produce a novel fusion protein between the last 15 amino acids of VP22 and GFP, termed GFP-VP22, which is integrated into the RF177 virus particles, suggesting that the information required for virus particle targeting is located in the last 15 amino acids of VP22 (Schlegel and Blaho, 2009). HSV-1(F) VP22 has two dileucine motifs, one at amino acids 235 and 236 and one at amino acids 251 and 252, and these motifs are required for the proper cytoplasmic localization of the virus within cells (Tanaka et al., 2012). The core region (amino acids 1-190) at the N-terminus of MDV VP22 is essential for virus spread, nuclear localization, histone association, and cell cycle regulation. However, amino acids 191-249 of VP22 are not essential for MDV transmission; rather, they facilitate efficient cell-to-cell spread. Amino acids 174-190 are essential for MDV VP22 functionality, and the IKIT motif (amino acids 159-162), located in the predicted $\beta$-strand, plays key roles in nuclear localization, histone association, and cell cycle arrest (Trapp-Fragnet et al., 2019) (Table 2).

TABLE 2 | VP22 function and its functional domain.

\begin{tabular}{|c|c|c|c|c|}
\hline Virus & Protein & Function & Functional domain & References \\
\hline \multirow[t]{7}{*}{ HSV-1 } & VP22 & Associates with cellular membranes & $120-225$ amino acids & Brignati et al., 2003 \\
\hline & & Virus particle targeting & The last 15 amino acids of VP22 & Schlegel and Blaho, 2009 \\
\hline & & Cytoplasmic localization & $\begin{array}{l}\text { Two dileucine motifs (amino acids } 235 \\
\text { and } 236 \text { and amino acids } 251 \text { and 252) }\end{array}$ & Tanaka et al., 2012 \\
\hline & & Stabilize the microtubule network & Not studied & Elliott and O'Hare, 1998 \\
\hline & & Inhibits CD1d recycling & Not studied & (Liu et al., 2016) \\
\hline & & Closely related to mitotic chromosomes & C-terminus & Ingvarsdottir and Blaho, 20 \\
\hline & & Associate directly with nucleoli & Not studied & López et al., 2008 \\
\hline \multirow[t]{4}{*}{ MDV } & VP22 & $\begin{array}{l}\text { Virus spread, nuclear localization, } \\
\text { histone association, and cell cycle } \\
\text { regulation }\end{array}$ & 1-190 amino acids & Trapp-Fragnet et al., 2019 \\
\hline & & $\begin{array}{l}\text { Nuclear localization, histone } \\
\text { association, and cell cycle arrest }\end{array}$ & The IKIT motif (amino acids 159-162) & Trapp-Fragnet et al., 2019 \\
\hline & & Regulates the cell cycle & Not studied & Trapp-Fragnet et al., 2014 \\
\hline & & Induces DNA double-strand breaks & C-terminus & Bencherit et al., 2017 \\
\hline BoHV-1 & VP22 & Promotes apoptosis of host tumor cells & Not studied & Qiu et al., 2005 \\
\hline
\end{tabular}




\section{Localization in Virions}

During herpesvirus infection, the envelope fuses with the cell membrane to allow viral particles to enter a cell. Most of the tegument and the envelope detach from the virus in the cytoplasm, releasing the nucleocapsid and some tegument proteins (Maurer et al., 2008). The tegument proteins of herpesviruses are generally divided into "inner" and "outer" tegument proteins. The inner tegument proteins are closely related to the nucleocapsid, while the outer membrane proteins are weakly related to the inner surface of the nucleocapsid and envelope. During PRV infection, the inner tegument proteins (added first during assembly), including pUL36, pUL37, and pUS3, remain associated with the capsid during viral entry, while outer tegument proteins such as pUL11, pUL47, pUL48, and pUL49 are lost (Granzow et al., 2005). Because VP22 interacts with the cytoplasmic tail of the glycoprotein at the Golgi apparatus to participate in secondary envelopment, VP22 is mainly located in the outer tegument close to the envelope in virions.

\section{VP22 Subcellular Localization}

The distribution of the VP22 in cells is dynamic. For example, during HSV-1 infection, the protein exhibits at least three different subcellular distributions: cytoplasm only, cytoplasm and nucleus, and nucleus only. VP22 is mainly distributed in the cytoplasm in the early stages of viral infection, but it migrates to the nucleus in the late stage of infection, and nuclear VP22 is more highly phosphorylated than cytoplasmic VP22 (Pomeranz and Blaho, 1999; Sugimoto et al., 2008). VP22 exhibits a diffuse distribution in the cytoplasm and nucleus in MDVinfected cells and accumulates in the nucleus when MDV-VP22 is overexpressed (Dorange et al., 2000). HSV-1 VP22 and BoHV1 VP22 are known to localize in the cytoplasm and the nucleus independently of other viral proteins (Harms et al., 2000; Blouin and Blaho, 2001).

One study found that VP22 is localized in the cytoplasm before microtubule rearrangement and in the nucleus after microtubule rearrangement. Drugs that stabilize microtubules can increase the accumulation of VP22 in the cytoplasm, and VP22 colocalizes with microtubules. Thus, it was concluded that the microtubule reorganization during HSV-1 infection promoted the nuclear localization of VP22. During HSV-1 infection, microtubule interaction may present a means by which VP22 avoids nuclear localization during the early phase of the replication cycle (Kotsakis et al., 2001). During non-viral infection conditions in vitro, HSV-1 VP22 is mainly localized in the cytoplasm; however, during mitosis, VP22 begins to associate with chromatin and becomes relatively fixed in one position after entering the nucleus. In live cell analysis experiments, VP22 protein has been found to be mainly located in acidic cell regions and distributed in puncta that move quickly through the cytoplasm. This punctate distribution may be related to vesicle transport in the secretory pathway and the trans-Golgi network (TGN) (Elliott and O'Hare, 1999; Brignati et al., 2003). VZV ORF9p is present in the TGN and plays a role in the secondary envelopment process (Che et al., 2013; Riva et al., 2013).

\section{ROLE OF VP22 IN THE VIRAL LIFE CYCLE}

\section{Effect of VP22 on Viral Gene Transcription}

During herpesvirus infection, the virus cooperates with cell transcriptional regulatory factors to synergistically regulate transcription initiation. Notably, the expression of the ICP4 gene is significantly lower in cells infected with VP22-knockout EHV-1 than in those infected with the parent virus (Okada et al., 2018).

The product of the HSV-1 UL41 gene, Virion Host Shutoff (VHS) protein, is an endoribonuclease that degrades mRNA during the early stages of infection and inhibits host protein synthesis (Su and Zheng, 2017; He et al., 2020). Earlier, a study found that vhs protein binds VP22 only in the presence of VP16 to form a VP22-VP16-vhs tripartite complex that promotes the translation of viral mRNA, but it does not block the degradation of mRNA by vhs. The presence or absence of VP16 or VP22 does not affect the stable state of VHS mRNA, while the presence of VP16 and VP22 can enhance expression of VHS protein for assembly into virions (Taddeo et al., 2007). Recently, research has reported that during infection, translation of vhs requires VP22 but not the VP22-VP16 complex, and coexpression of VP16 and VP22 can rescue the cytoplasmic localization of vhs mRNA but has failed to rescue vhs translation. The VP22-VP16-vhs complex uses nuclear retention of vhs mRNA instead of translation as a rescue target (Elliott et al., 2018).

Other studies found that in the absence of VP22, not only are early and late transcripts retained in the nucleus through VHS-dependent mechanisms, but this feature extends to cell transcripts that are not effectively degraded by VHS. Moreover, it reveals the true role of VP22 in the regulation of VHS activity, which specifically rescues the cytoplasmic localization of L transcripts rather than their hyper-degradation (Pheasant et al., 2018). Deletion of the HSV-1 UL49 gene generates three inactive VHS mutants: two lacking codons $22-75$ of the UL41 gene and another with a codon frameshift at site 286. All the mutations cause vhs to be inactive in the absence of VP22 (Sciortino et al., 2007). In addition, deletion of the HSV-1 UL49 gene slightly decreases viral mRNA levels and causes defects in polysome assembly that are independent of mRNA abundance, but these defects can be rescued by a secondary compensatory frameshift mutation in vhs, indicating the existence of functional interplay between VP22 and vhs with regard to both accumulation and translation of viral mRNA (Mbong et al., 2012). The opposite is a study showing a replication-competent VP22 deletion mutant virus constructed by homologous recombination carrying a wildtype (Wt) vhs gene and no other gross mutations. Therefore, the mode of virus rescue affects the acquisition of secondary mutations (Ebert et al., 2013).

\section{VP22 Affects Viral Protein Synthesis}

VP22 affects viral gene expression and protein synthesis. Deletion of HSV-1 VP22-encoding gene (UL49) can lead to modest reductions in levels of glycoproteins $\mathrm{gD}$ and $\mathrm{gB}$. Experimental data indicate that VP22 is involved in recruiting ICP0 (and 
potentially ICP4) to specific cytoplasmic domains and is necessary to assemble the immediate early proteins ICP0 and ICP4 between the envelopes of HSV particles. In addition, VP22 influences both the intracellular levels and localization of ICP0 (Elliott et al., 2005). Further research has shown that VP22 enhances the accumulation of $\mathrm{gE}$ and $\mathrm{gD}$ mRNA in the early stage of HSV-1 infection but has no effect in the late stage of infection; however, deletion of VP22 causes the synthesis of most proteins to cease in the late stage of infection, and this decline in protein synthesis is not related to abnormal apoptosis or increased eIF-2a phosphorylation. Overall, VP22 promotes viral mRNA accumulation in early stages and protein synthesis in late stages of infection (Duffy et al., 2009).

HSV-1 VP22 can interact with the TATA box binding proteinassociated factor (TAF-I) protein to inhibit the assembly of nucleosomes on DNA, but it does not affect the inhibitory activity of the histone acetyltransferase inhibitor INHAT on the histone acetyltransferase P300 or PCAF. TAF-I can also block the nonspecific binding of VP22 to DNA. Since overexpression of TAF-I interferes with the process of HSV-1 infection in transfected cells, researchers have speculated that VP22 may interfere with TAFI-mediated ribosomal binding to mRNA in the early stage of HSV infection (van Leeuwen et al., 2003). This phenomenon suggests that VP22 may promote the expression of viral genes by maintaining important regulatory sequences in viral gene promoters in a nucleosome-free state so that they can be accessed by transcription factors.

In one study, a VP22 251 and 252 dileucine motif mutant and a VP22 restoration virus of the wild-type HSV-1 strain HSV-1(F) (viruses: VP22LL251AA and VP22LL251AA-repair, respectively) were inoculated into the brains of mice. The $50 \%$ lethal dose (LD50) of VP22LL251AA in the brain was approximately $10^{3}$ fold lower than VP22LL251AA-repair at 3 and 5 days after infection. In addition, viral antigens were detected in many regions of the brain in VP22LL251AA-repair-infected mice but only in restricted regions of the brain in VP22LL251AA-infected mice, confirming that VP22 is a significant neurovirulence factor in vivo (Tanaka et al., 2012).

\section{VP22 Influences Virion Assembly Interactions With Viral Tegument Proteins}

To date, research examining how VP22 is assembled into virions has revealed inconsistent results. Early studies have suggested that an 89-amino acid sequence at the C-terminus of HSV-1 VP22 is sufficient for packaging a small amount of VP22 into virions, but VP22 must interact with VP16 to be packaged into virions at wild-type levels, indicating that VP16 is important for this process (Hafezi et al., 2005). In contrast, a study assessing the effect of HSV-1 VP22 binding with VP16 or gE on VP22 packaging into virions and related compartmentalization patterns later revealed that VP22 does not need to interact with VP16 to be packaged into virions (O'Regan et al., 2007b).

VZV ORF9p can interact with amino acids 1-43 of the IE62 acidic transactivation domains (TADs) and with tubulin, suggesting a model for ORF9p function in which ORF9p forms a complex with IE62 and possibly other tegument proteins in the cytoplasm at late stages of infection (Cilloniz et al., 2007). HSV VP22 can directly interact with the TAD in the C-terminus of VP16. When VP22 and VP16 are coexpressed in the absence of other viral proteins, they colocalize around the nuclear membrane, which may reflect their functions in viral assembly (Elliott et al., 1995). VZV ORF9p interacts with amino acids 549-793 at the C-terminus of ORF11p, and both proteins are located mainly in the trans-Golgi vesicle region in infected cells. This region participates in the secondary envelopment of viral particles, suggesting that the ORF9 protein plays key roles in VZV particle membrane assembly and secondary envelopment (Che et al., 2013).

Deletion of PRV pUL21 reduces the amounts of pUL46, pUL49 and pUS3 packaged into virions by $80-90 \%$, indicating that pUL21 is very important for pUL49 packaging into virions (Michael et al., 2007). The HSV-1 UL16 gene encodes a protein that can interact with VP22, and deletion of the UL16 gene can disrupt the participation of VP22 in viral packaging. Deletion of VP22 reduces the packaging of gE and VP16 but not the packaging or expression of the UL16 gene, which confirms that the assembly of VP22 into virions depends on UL16 (Starkey et al., 2014).

Earlier studies found that ICP0 could be easily detected in wild-type (Wt) virus particles, but ICP0 could not be detected in virus preparations lacking the major tegument protein VP22, suggesting that VP22 is somehow involved in the assembly of ICP0 (Elliott et al., 2005). Furthermore, as VP22 is required for assembly of the virion of the immediate early protein ICP0, any interaction that affects the recruitment of VP22 to viral particles may indirectly affect the assembly of ICP0 (Maringer and Elliott, 2010).

VZV ORF9p with a point mutation has been found to be able to interact with and be phosphorylated by the CKII-like serine/threonine kinase ORF47p during infection (Oral et al., 2016), but mutation of the amino acid E85 in ORF9p severely affects the assembly and release of the virus. Therefore, the phosphorylation of amino acid E85 in ORF9p is essential for primary envelopment of VZV virions and nucleation of virions during viral transmission (Riva et al., 2013).

\section{Interactions With Viral Glycoproteins}

Entry of most, but not all, herpesviruses into cells requires the envelope glycoprotein gD (Pannhorst et al., 2018). HSV VP22 can specifically bind to the cytoplasmic tail of $\mathrm{gD}$, and this binding depends on the arginine and lysine residues at positions 5 and 6 of the gD cytoplasmic tail. In addition, the HSV-1 capsid binds to the cytoplasmic tail of $\mathrm{gD}$ and exhibits a similar sequence dependence. Therefore, VP22 can act as a linker protein to mediate the interaction of the HSV capsid with gD (Chi et al., 2005). Subsequently, a team confirmed by reciprocal pull-down experiments that HSV-1 VP22 interacts with gD in a specific manner, and these interactions require the CT domain of $\mathrm{gD}$ (Farnsworth et al., 2007). Although gD has been described as a VP22 binding partner, one study has not been able to repeat the interaction between VP22-gD (Maringer et al., 2012).

A study revealed that a mutant form of HSV-1 lacking 14 residues of VP22 (and thus unable to interact with $\mathrm{gE}$ ) does not 
grow well in epithelial cells; in fact, the growth phenotype was the same as that observed after deletion of the complete VP22 ORF, suggesting that $\mathrm{gE}$ is essential for packaging of VP22 into virions (Stylianou et al., 2009). To further confirm the role of HSV-1 $\mathrm{VP} 22$ /gE binding in promoting viral particle packaging, a team used site-directed mutagenesis to specifically destroy the binding activity of VP22 and gE, and their findings confirmed that VP22 is packaged into virions independently of any interaction with gE (O’Regan et al., 2010). HSV-1 VP22 has also been reported to interact with the glycoproteins gE and gM (O'Regan et al., 2007a; Stylianou et al., 2009). The glycoprotein-binding domain of VP22 is conserved among all VP22 homologs, suggesting that the gE-VP22-gM complex may be important for alphaherpesvirus replication (Mouzakitis et al., 2005).

In addition, studies have demonstrated that the C-terminus of PRV VP22 binds to the cytoplasmic tails of $\mathrm{gE}$ and gM. Deletion of VP22 does not affect viral maturation or secondary envelopment in the cytoplasm. Under normal infection conditions, VP22 is effectively packed into virions; however, the absence of the gE-gl complex and gM affects secondary envelopment and prevents VP22 from being packaged into virions (Fuchs et al., 2002). BoHV-1 VP22 can interact with the glycoprotein gN encoded by the UL49.5 gene without relying on gM. In the absence of $\mathrm{gM}$, the assembly of $\mathrm{gN}$ into the viral envelope may be mediated by an interaction of amino acids 80-96 in the intracellular domain of gN with VP22 (Pannhorst et al., 2018).

The herpesvirus tegument exerts the roles of other viral matrix proteins by interacting with the capsid on one side and the cytoplasmic tails of envelope glycoproteins on the other side, connecting these structural components for the final envelopment process and ensuring the integrity of the virus particle (Klupp et al., 2017). The envelope formation and scission involve the participation of multiple viral proteins and cellular ESCRT devices. For HSV-1 and PRV, a number of tegument and envelope proteins are assigned roles in the envelopment, and may provide a pathway for the recruitment of ESCRT complexes, which contains five tegument proteins (encoded by HSV-1 UL21, UL46, UL47, UL48, and UL49) (Owen et al., 2015; Barnes and Wilson, 2019).

Studies have shown that VP22, ICP0, gE, and $\mathrm{gM}$ are present within the same complex in infected cells, and that although VP22 is not required for virus assembly, it is fundamental to the formation of this multicomponent complex (Maringer et al., 2012). This finding reveals the existence of specific interactions between herpesvirus the cytoplasmic tails of envelope glycoproteins and tegument protein VP22. These interactions may facilitate the secondary envelope of the herpesvirus viral particles during maturation, thereby ensuring the integrity of the virus particles (Figure 2 and Table 3 ).

\section{Interactions With Cellular Protein}

VZV ORF9p can interact with cell adapter protein complex 1 (AP-1), and leucine 231 in ORF9p has been identified as critical for this interaction. Disruption of ORF9p binding to AP1 via point mutation of ORF9p severely impairs viral growth, most likely by preventing effective viral secondary envelopment

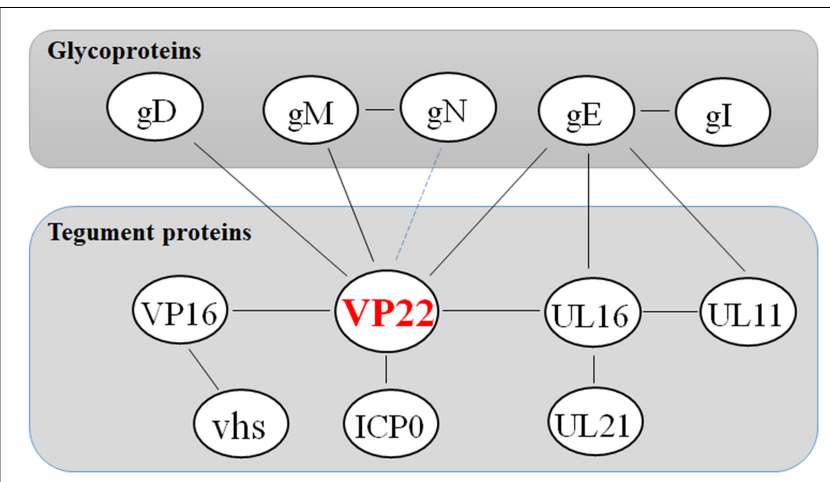

FIGURE 2 | Network of protein-protein interaction around the tegument protein VP22. Some inspiration for this figure was obtained from a previous article (Maringer et al., 2012).

(Lebrun et al., 2018). MDV VP22 and HSV-2 VP22 also interact with AP-1 (Qiu et al., 2005). In HSV-1 infected cells, VP22 may be activated via phosphorylation mediated by protein kinases encoded by the CKII and UL13 genes (Elliott et al., 1996; Asai et al., 2007). In a study in which a high multiplicity of infection (MOI) and actinobacteria were used to artificially increase the amount of virus in infected cells and stop the infection process, the tegument protein VP22 of HSV-1 was found to be phosphorylated upon viral entry into cells, which mediated VP22 dissociation from the virion in vitro. With the UL13 mutant virus, the release of VP22 was significantly impaired, suggesting that the protein kinase encoded by the UL13 gene is a major protein kinase facilitating the separation of VP22 from virions (Morrison et al., 1998) (Table 4).

\section{VP22 Promotes Cell-to-Cell Viral Transmission}

Many viruses can trigger remodeling of the host cytoskeleton in their early life cycle to promote efficient entry into the host cell and transport to the nucleus (Zandi et al., 2013; Cirillo et al., 2017; Dharan and Campbell, 2018). HSV1 VP22 is transiently expressed in cells, colocalizes with a unique cytoplasmic filamentous structure, and can induce microtubule recombination into a thick bundle structure. Analysis of the infected cells further showed that VP22 colocalized with microtubules during the infection and induced microtubule acetylation. Moreover, the resistance of VP22induced microtubule bundles to microtubule-depolymerizing agents and cold treatment was stronger than that of normal cell microtubules, suggesting that VP22 could stabilize the microtubule network (Elliott and O'Hare, 1998).

PRVs lacking tegument proteins such as VP13/14, VP16, and VP22 can enter cells but cannot translocate normally to the nucleus (Mettenleiter, 2002). A team investigated the protein profile of VP22-null (PRV 175) virions for differences relative to wild-type virions, the results show that in the absence of VP22, tegument assembly compensates in a limited manner by increasing incorporation of cellular actin (del Rio et al., 2005). The structures and functions 
TABLE 3 | Tegument protein VP22 and its interacting virus protein.

\begin{tabular}{|c|c|c|c|c|}
\hline Virus & Protein & $\begin{array}{l}\text { Interacting } \\
\text { Virus protein }\end{array}$ & Function & References \\
\hline \multirow[t]{6}{*}{ HSV-1 } & VP22 & $g E$ & Packaged into virions & Stylianou et al., 2009 \\
\hline & & gM & VP22-gM association may be dynamic, packaged into virions & Mouzakitis et al., 2005 \\
\hline & & gD & Mediates the interaction of the HSV-1 capsid with gD & Chi et al., 2005 \\
\hline & & ICPO & VP22 is required for virion assembly of ICPO & Maringer and Elliott, 2010 \\
\hline & & VP16 & This interaction is not required to package VP22 into virion; & O'Regan et al., 2007b \\
\hline & & UL16 & Packaged VP22 into virions & Starkey et al., 2014 \\
\hline \multirow[t]{2}{*}{ PRV } & VP22 & $g E$ & Packaged into virions & Fuchs et al., 2002 \\
\hline & & $g \mathrm{M}$ & Packaged into virions & Fuchs et al., 2002 \\
\hline $\mathrm{BoHV}-1$ & VP22 & $\mathrm{gN}$ & In the absence of $\mathrm{gM}$, the assembly of $\mathrm{gN}$ into viral membrane & Pannhorst et al., 2018 \\
\hline \multirow[t]{3}{*}{ VZV } & ORF9p & IE62 & Forms a complex with other tegument proteins in the cytoplasm at late stages of infection & Cilloniz et al., 2007 \\
\hline & & ORF11p & VZV particle membrane assembly and secondary envelopment & Che et al., 2013 \\
\hline & & ORF47p & The primary envelopment of VZV virions and the nucleation of virions & Oral et al., 2016 \\
\hline
\end{tabular}

TABLE 4 | Tegument protein VP22 and its interacting cellular protein.

\begin{tabular}{|c|c|c|c|c|}
\hline Virus & Protein & Interacting cellular protein & Function & References \\
\hline \multirow[t]{4}{*}{ HSV-1 } & VP22 & TAF-1 & Inhibits the assembly of nucleosomes on DNA & van Leeuwen et al., 2003 \\
\hline & & NMIIA & Lined up with filaments containing NMI IA & van Leeuwen et al., 2002 \\
\hline & & cGAS & Inhibits the enzymatic activity of cGAS & Huang et al., 2018 \\
\hline & & AlM2 & Prevents AIM2 oligomerization & Maruzuru et al., 2018 \\
\hline BoHV-1 & VP22 & Histone $\mathrm{H} 4$ & Reducing $\mathrm{H} 4$ histone acetylation & Ren et al., 2001 \\
\hline VZV & ORF9p & $\mathrm{AP}-1$ & Effective viral secondary envelopment & Lebrun et al., 2018 \\
\hline
\end{tabular}

of the core domains of the HSV-1 VP22 and the MHV68 ORF52 protein are very similar, indicating that both proteins can serve as adaptors to bind different proteins. VP22 and ORF52 can interact with many proteins and regulate protein localization in cells to participate in the assembly of a protein scaffold consisting of other tegument proteins and to establish a protein bridge between the capsid and the lipid envelope. This assembly process may be important for intracellular transport of proteins along microtubules (Hew et al., 2015).

Myosin II present in non-muscle cells is called non-muscle myosin II (NMIIA). In addition to serving as a molecular motor for various molecular movements in cells, NMIIA participates in cell migration, adhesion, cytokinesis, vesicle secretion, Golgi budding, and other physiological activities (Vicente-Manzanares et al., 2009; Arii et al., 2010). A study found that viral particles of an HSV-1 recombinant virus expressing the fusion protein GFP-VP22 could be observed that colocalized with a population of NMIIA in sites proposed to be viral assembly compartments in the late stage of infection. In addition, GSTpulldown experiments of cell samples and prokaryotic samples demonstrated that VP22 could interact with NMIIA, but it remained formally possible that the NMIIA-VP22 association was indirect via NMIIA interactions with one of the other bound species (van Leeuwen et al., 2002).

Apoptosis in the early stage of viral infection prevents replication of the virus, but apoptosis in the late stage of infection is beneficial for the release and spread of progeny virus (Oral et al., 2016; Zhou et al., 2017). Transient expression of BoHV-1 VP22 in NXS2 cells does not affect the cell cycle, and analyses of caspase- 3 activity and apoptosis have suggested that VP22 induces apoptosis in host tumor cells by upregulating the expression ratio of Bax to Bcl-2 (Qiu et al., 2005). These results suggest that VP22 may promote the spread of viruses by stimulating apoptosis in the late stage of viral infection.

The proteins encoded by the HSV-1 UL47, UL49, and US11 genes can bind to RNA in host cells and then be packaged into viral particles that are capable of carrying the proteins to newly infected cells for expression, thereby creating an environment that is conducive to effective triggering of infection (Sciortino et al., 2002). A study constructed the HSV-1 UL49 deletion and reverted strain viruses and analyzed their growth in cultured cells and mouse cornea compared with the parental strains. VP22 is dispensable for virus replication at high multiplicities of infection (MOIs), and analyses of plaque morphology and intraand extracellular multistep growth identified a role for VP22 in viral spread during HSV-1 infection at low MOIs. In addition, viral spread in the mouse cornea was significantly reduced upon infection with the UL49-null virus compared with infection with the wild-type and UL49-repaired viruses, identifying a role for VP22 in viral spread in vivo and in vitro (Duffy et al., 2006). A team has constructed different BoHV-1 mutants with deletions of UL49 or gE, or both, to investigate the function of BoHV1 VP22 in viral cell-to-cell spread. Deletion of gE resulted in a $53 \%$ reduction in plaque diameter, while a single deletion of UL49 resulted in a $52 \%$ reduction. However, the simultaneous deletion of $\mathrm{gE}$ and UL49 resulted in a $83 \%$ reduction in the diameter of the virus plaque, indicating that gE and VP22 are two equally 


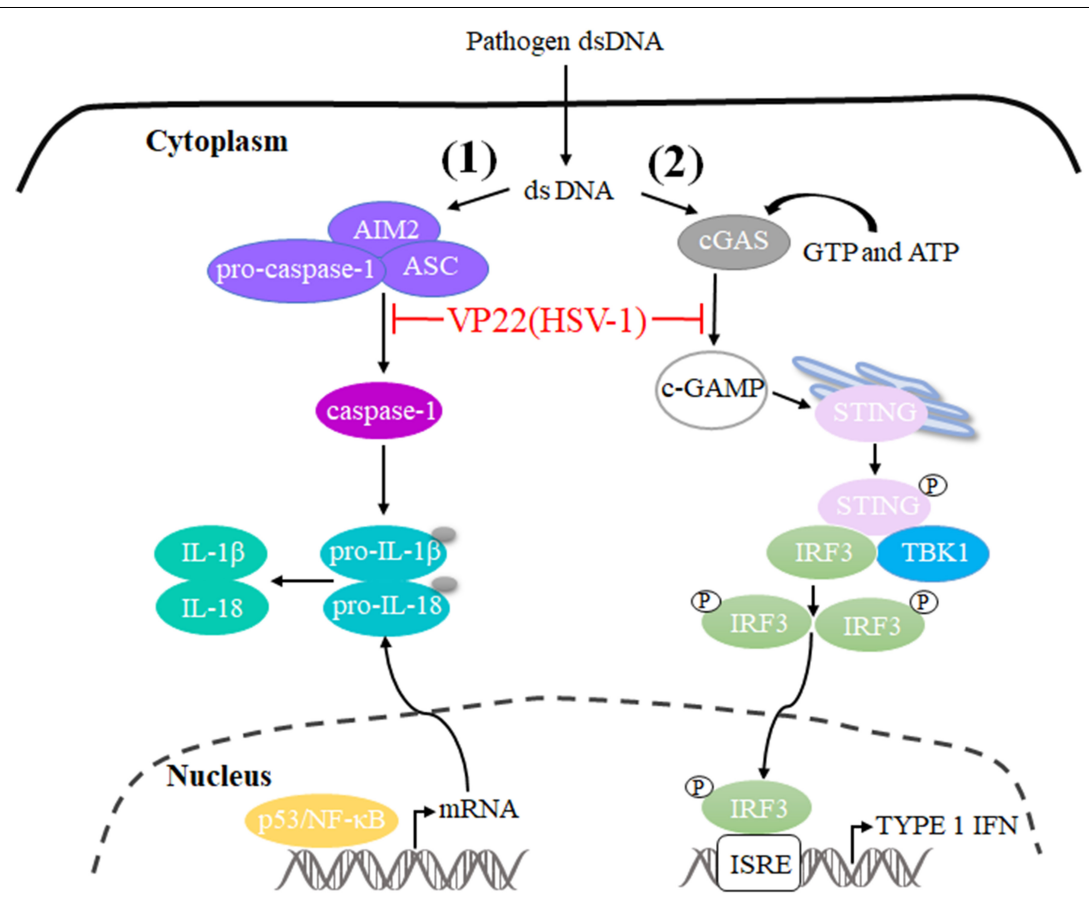

FIGURE 3 | Schematic diagram of pathogen-derived molecules enabling VP22 to evade the DNA-sensing pathway in cells. (1) cGAS is activated after it binds to dsDNA and uses ATP and GTP to generate cGAMP through enzymatic activity. cGAS is responsible for activation of the binding protein STING. Phosphorylated STING begins to recruit TBK1 to activate IRF3, and phosphorylated IRF3 enters the nucleus to activate the interferon-stimulated response element (ISRE), thereby producing type I interferon to fight pathogens. HSV-1 VP22 binds to and inhibits the enzymatic activity of cGAS, thereby enabling evasion of the host's innate immune response. (2) AIM2 is a pattern recognition receptor that can recognize dsDNA in the cytoplasm and bind to the linker protein ASC and pro-caspase-1 to form the AIM2 inflammasome (AIM2-ASC-Pro-caspase-1), which activates caspase-1; activated caspase-1 can cleave pro-IL-1 13 and pro-IL-18, which leads to the maturation and secretion of the inflammatory factors IL-1 $\beta$ and IL-18. HSV-1 VP22 can interact with AIM2 and prevent its oligomerization, thereby inhibiting the activation of AIM2-dependent inflammatory bodies.

important factors for BoHV-1 cell-to-cell spread and that both are likely to act independently of each other in a critical pathway of virus cell-to-cell spread (Kalthoff et al., 2008).

\section{VP22 Facilitates the Viral Life Cycle Through Innate Immune Evasion}

The innate immune system is the first line of host defense against invading pathogens. It is also the basis for adaptive immune activation and plays an important role in the elimination of viruses from hosts. Under the long-term selective pressure of host immune activity, viruses have developed a variety of mechanisms to antagonize the antiviral ability of the host and thereby promote viral infection and replication (Sun et al., 2013; Orzalli et al., 2015; Chiang et al., 2018). Cyclic GMP-AMP (cGAMP) levels decrease during HSV-1 infection, indicating that there is at least one viral component capable of inhibiting cGAMP synthase (cGAS) activity. Subsequently, VP22 directly binds to and inhibits cGAS enzymatic activity, leading to the downregulation of IFN$\beta$ production and thereby inhibiting cGAS/STING-mediated natural antiviral immune pathways (Huang et al., 2018). In addition, a study constructed a mutant virus lacking VP22 (HSV-1 $\triangle$ VP22), which activates and induces AIM2-dependent secretion of IL-1 $\beta$ and IL-18. They found that VP22 could interact with AIM2 and prevent its oligomerization, thereby inhibiting activation of the AIM2-dependent inflammasome. HSV-1 $\triangle$ VP22 infection results in diminished viral yields in vivo, but HSV-1 $\triangle \mathrm{VP} 22$ replication is largely restored in AIM2-deficient mice, revealing that HSV-1 evades host immune responses to enable efficient viral replication in vivo (Maruzuru et al., 2018) (Figure 3).

Many herpesvirus viral proteins can evade the innate immune response of the host (Christensen et al., 2016; Liu et al., 2018; Yang et al., 2019; You et al., 2019). In addition to playing an important role in innate immune evasion, VP22 can also play a role in specific immune evasion (Liu et al., 2016). A previous study on HSV-1 infection has revealed that compared with wildtype strains, mutant strains lacking VP22 have impaired ability to inhibit CD1d-mediated antigen presentation. This phenomenon can be reversed after VP22 is restored, indicating that VP22 inhibits CD1d recycling (Liu et al., 2016).

\section{Other Functions of VP22 Chromatin Binding}

Chromatin, a material with a linear structure composed of DNA, histones, non-histone proteins, and a small amount of RNA, is found in interphase nuclei and contains the genetic material of interphase cells (Clapier and Cairns, 2009). Previous studies have shown that the molecular weights of HSV VP22 and histones are 
very similar during gel electrophoresis and that the C-terminal sequence of VP22 and histone folding domain sequence are very similar. Therefore, VP22 may localize in the nucleus in a manner similar to that of histones and be closely related to mitotic chromosomes (Elliott and O’Hare, 2000; López et al., 2008; Ingvarsdottir and Blaho, 2010).

To investigate the relationship between HSV-1 VP22 and nucleoli, one study detected the localization of nucleolar proteins and viral proteins during viral infection and found that the VP22 present in VP22-expressing Vero cells surrounded nucleoli; in addition, a portion of the VP22 localized to areas of altered nucleoli and to marginalized chromatin in nuclei at 4 and 6 hours post-infection (hpi). These findings indicate that VP22 might associate directly with nucleoli and that nuclear VP22 targets unique subnuclear structures early during HSV-1 infection ( $<6$ hpi) (López et al., 2008). Given that VP22 closely associates with chromosomes during mitosis and is located in the marginalized chromatin region, it may affect chromosomes by interacting with DNA-binding proteins.

Histone modification plays important roles in chromatin recombination, cell cycle control, and gene regulation. In BoHV1-infected or VP22-expressing cells, VP22 can bind to histones and nucleosomes, thus reducing $\mathrm{H} 4$ histone acetylation. Since VP22 and histones have similar epitopes, it has been speculated that BoHV-1 VP22 may play a regulatory role in the replication process of TAF-1. MDV VP22 has the same function as BoHV1 VP22 during interactions with histones (Trapp-Fragnet et al., 2014). Interestingly, a positive correlation between cell cycle modulation and VP22 histone association, but no relationship with MDV cell-to-cell spread function, has been observed (Trapp-Fragnet et al., 2019).

\section{Regulation of the Cell Cycle}

Viral proteins can impede the life cycles of host cells through multiple cellular regulatory pathways that affect cell growth, and viruses use the functional proteins synthesized during the process to create the most suitable environment for viral replication (Liang et al., 2002; Yu J. et al., 2015; Wang Z. et al., 2018). Studies have shown that a recombinant MDV expressing a VP22 with a C-terminal GFP tag is highly attenuated effect in vivo, indicating that VP22 plays a role in MDV-induced tumorigenesis (Jarosinski et al., 2012). In addition, another study has found that MDV infection can arrest cells in S phase of the cell cycle, thereby disrupting cell cycle progression and slowing cell proliferation. In addition, $90 \%$ of cells that transiently express VP22 undergo cell cycle changes, indicating that VP22 is a major cell cycle regulator encoded by MDV (Trapp-Fragnet et al., 2014). Cell cycle arrest has been shown to be beneficial for herpesvirus replication, and overexpression of MDV VP22 can lead to cell cycle arrest in HSV-1- and VZV-infected cells (Flemington, 2001). Cell cycle arrest is related to DNA damage signals, which are usually triggered during viral infection, and the DNA damage response pathway is a priority target for herpesviruses (Mohni et al., 2013). A recombinant virus lacking the ability to induce DNA damage has showed defects in inducing tumors, suggesting that DNA damage induction may be involved in the tumorigenicity of MDV. Modification of the C-terminus of MDV VP22 disrupts

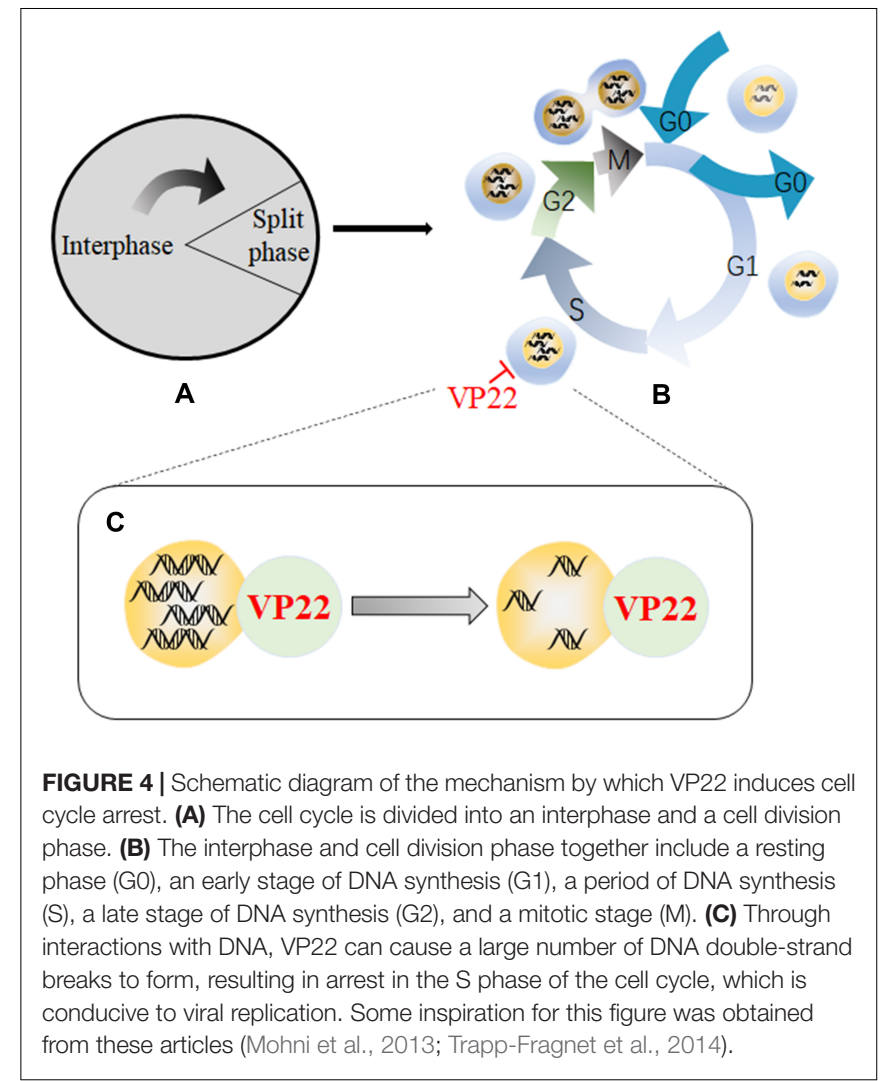

the ability of VP22 to trigger DNA damage. Therefore, the VP22 C-terminus is essential for the induction of DNA damage, and VP22 is a major viral determinant associated with DNA damage (Bencherit et al., 2017). Therefore, the arrest in S phase induced by VP22 may produce a large number of DNA double-strand breaks (DABs) (Figure 4).

\section{CONCLUSION}

The VP22 protein, a structural protein in alphaherpesviruses, is one of the most abundant tegument proteins, with more than 2000 copies in each virion (Heine et al., 1974). The replication process of herpesviruses includes adsorption, penetration, shelling, biosynthesis, virion assembly, maturation, and release. This virion assembly is a virus-specific process and can be used as an antiviral drug target. VP22 can interact with many tegument proteins and glycoproteins to regulate the assembly of viral particles, thereby mediating the movement of capsid proteins from the outer nuclear membrane of the cell to the Golgi apparatus and promoting the formation of mature viral particles, we suspect that VP22 can be used as a target for future research on antiviral drugs.

During the viral life cycle, VP22 participates in virion assembly, regulates the cell cycle, and functions in the transcriptional regulation of viral genes. VP22 can induce a large number of DNA double-strand breaks, and subsequent DDRs are beneficial for MDV replication, which is conducive to 
oncogenicity of MDV (Bencherit et al., 2017). In addition, VP22 can induce apoptosis of host tumor cells and thus facilitate the spread of the virus. These findings reveal a new mechanism of viral spread between cells and provide novel ideas and directions for further research on the treatment of diseases caused by herpesvirus infection.

In the early years, the literature has reported that proteins larger than $-40 \mathrm{kda}$ require an exposed NLS to enter the nucleus. The predicted molecular weight of HSV-1 VP22 is $32 \mathrm{kDa}$, which is below the size limit for passive diffusion through nuclear pores. However, not all proteins that fit the size of the protein can shuttle freely. Some proteins have a relatively small molecular weight but a special amino acid signal sequence, so they can enter the nucleus through active transport; or there is no signal sequence itself, but it can be associated with other signals, resulting in the entry of the combined material into the nucleus through active transport (Timney et al., 2016), then VP22 may need a special amino acid signal sequence to enter the nucleus through active transport.

Successful immune escape is the main factor underlying chronic herpesvirus infection. In recent years, there have been reports in the literature that VP22 participates in innate immune evasion. VP22 interacts with RNA and functions in the transport of viral mRNA, and packaged RNA can be expressed in newly infected cells (Sciortino et al., 2002). We further speculate that VP22 may inhibit innate immunity by transporting mRNA molecules that are translated into viral proteins in adjacent cells to suppress immune responses before the pattern recognition receptor pathway can recognize the newly infecting virus.

\section{REFERENCES}

Arii, J., Goto, H., Suenaga, T., Oyama, M., Kozuka-Hata, H., Imai, T., et al. (2010). Non-muscle myosin IIA is a functional entry receptor for herpes simplex virus-1. Nature 467, 859-862. doi: 10.1038/nature09420

Asai, R., Ohno, T., Kato, A., and Kawaguchi, Y. (2007). Identification of proteins directly phosphorylated by UL13 protein kinase from herpes simplex virus 1. Microbes Infect. 9, 1434-1438. doi: 10.1016/j.micinf.2007. 07.008

Barnes, J., and Wilson, D. W. (2019). Seeking closure: How do herpesviruses recruit the cellular ESCRT apparatus? J. Virol. 93:e00392-19.

Bencherit, D., Remy, S., Le Vern, Y., Vychodil, T., Bertzbach, L. D., Kaufer, B. B., et al. (2017). Induction of DNA damages upon Marek's disease virus infection: implication in viral replication and pathogenesis. J. Virol. 91:e01658-17.

Bigalke, J. M., and Heldwein, E. E. (2016). Nuclear Exodus: Herpesviruses Lead the Way. Annu. Rev. Virol. 3, 387-409. doi: 10.1146/annurev-virology-110615042215

Blouin, A., and Blaho, J. A. (2001). Assessment of the subcellular localization of the herpes simplex virus structural protein VP22 in the absence of other viral gene products. Virus Res. 81, 57-68. doi: 10.1016/s0168-1702(01)00355-0

Bortz, E., Wang, L., Jia, Q., Wu, T. T., Whitelegge, J. P., Deng, H., et al. (2007). Murine gammaherpesvirus 68 ORF52 encodes a tegument protein required for virion morphogenesis in the cytoplasm. J. Virol. 81, 10137-10150. doi: 10.1128/jvi.01233-06

Brignati, M. J., Loomis, J. S., Wills, J. W., and Courtney, R. J. (2003). Membrane association of VP22, a herpes simplex virus type 1 tegument protein. J. Virol. 77, 4888-4898. doi: 10.1128/jvi.77.8.4888-4898.2003

Chang, C. D., Lin, P. Y., Liao, M. H., Chang, C. I., Hsu, J. L., Yu, F. L., et al. (2013). Suppression of apoptosis by pseudorabies virus Us3 protein kinase through the activation of PI3-K/Akt and NF-kappaB pathways. Res. Vet. Sci. 95, 764-774. doi: $10.1016 /$ j.rvsc.2013.06.003
By introducing specific mRNA into target cells, VP22 may prepare cells for the arrival of herpesvirus. However, further investigations are needed in the future to elucidate the details of this mechanism.

Further elaboration of the function and mechanism of VP22 will provide important reference data on the life cycles of herpesviruses in host cells and the interactions between pathogens and host cell molecules.

\section{AUTHOR CONTRIBUTIONS}

LP and AC contributed to the design of the manuscript. SM, XO, QY, YW, RJ ML, DZ, SC, and QG provided ideas contributing to the conception of this manuscript. BT helped to create the figures. MW modified the manuscript. All the authors read and approved the final manuscript for publication.

\section{FUNDING}

This work was supported by the National Natural Science Foundation of China (31872476), the China Agricultural Research System (CARS-42-17), the Sichuan Veterinary Medicine and Drug Innovation Group of China Agricultural Research System (SCCXTD-2020-18), and Integration and Demonstration of Key Technologies for Goose Industrial Chain in Sichuan Province (2018NZ0005).

Che, X., Oliver, S. L., Reichelt, M., Sommer, M. H., Haas, J., Roviš, T. L., et al. (2013). ORF11 protein interacts with the ORF9 essential tegument protein in varicella-zoster virus infection. J. Virol. 87, 5106-5117. doi: 10.1128/jvi.0010213

Che, X., Reichelt, M., Sommer, M. H., Rajamani, J., Zerboni, L., and Arvin, A. M. (2008). Functions of the ORF9-to-ORF12 gene cluster in varicella-zoster virus replication and in the pathogenesis of skin infection. J. Virol. 82, 5825-5834. doi: 10.1128/jvi.00303-08

Chi, J. H. I., Harley, C. A., Mukhopadhyay, A., and Wilson, D. W. (2005). The cytoplasmic tail of herpes simplex virus envelope glycoprotein D binds to the tegument protein VP22 and to capsids. J. Gen. Virol. 86, 253-261. doi: 10.1099/ vir.0.80444-0

Chiang, J. J., Sparrer, K. M. J., van Gent, M., Lässig, C., Huang, T., Osterrieder, N., et al. (2018). Viral unmasking of cellular 5S rRNA pseudogene transcripts induces RIG-I-mediated immunity. Nat. Immunol. 19, 53-62. doi: 10.1038/ s41590-017-0005-y

Christensen, M. H., Jensen, S. B., Miettinen, J. J., Luecke, S., Prabakaran, T., Reinert, L. S., et al. (2016). HSV-1 ICP27 targets the TBK1-activated STING signalsome to inhibit virus-induced type I IFN expression. EMBO J. 35, 1385-1399. doi: 10.15252/embj. 201593458

Cilloniz, C., Jackson, W., Grose, C., Czechowski, D., Hay, J., and Ruyechan, W. T. (2007). The varicella-zoster virus (VZV) ORF9 protein interacts with the IE62 major VZV transactivator. J. Virol. 81, 761-774. doi: 10.1128/jvi.01 274-06

Cirillo, L., Gotta, M., and Meraldi, P. (2017). The elephant in the room: the role of microtubules in cancer. Adv. Exp. Med. Biol. 1002, 93-124. doi: 10.1007/9783-319-57127-0_5

Clapier, C. R., and Cairns, B. R. (2009). The biology of chromatin remodeling complexes. Annu. Rev. Biochem. 78, 273-304.

Crump, C. (2018). Virus assembly and egress of HSV. Adv. Exp. Med. Biol. 1045, 23-44. doi: 10.1007/978-981-10-7230-7_2 
Dargan, D. (1986). "The structure and assembly of herpesviruses," in Electron Microscopy of Proteins: Viral Structure, eds J. R. Harris and R. W. Horne (London: Academic Press), 359-437.

del Rio, T., DeCoste, C. J., and Enquist, L. W. (2005). Actin is a component of the compensation mechanism in pseudorabies virus virions lacking the major tegument protein VP22. J. Virol. 79, 8614-8619. doi: 10.1128/jvi.79.13.86148619.2005

del Rio, T., Werner, H. C., and Enquist, L. W. (2002). The pseudorabies virus VP22 homologue (UL49) is dispensable for virus growth in vitro and has no effect on virulence and neuronal spread in rodents. J. Virol. 76, 774-782. doi: 10.1128 /jvi.76.2.774-782.2002

Dharan, A., and Campbell, E. M. (2018). Role of microtubules and microtubuleassociated proteins in HIV-1 Infection. J. Virol. 92:e00085-18.

Dorange, F., El Mehdaoui, S., Pichon, C., Coursaget, P., and Vautherot, J. F. (2000). Marek's disease virus (MDV) homologues of herpes simplex virus type 1 UL49 (VP22) and UL48 (VP16) genes: high-level expression and characterization of MDV-1 VP22 and VP16. J. Gen. Virol. 81, 2219-2230. doi: 10.1099/0022-131781-9-2219

Dorange, F., Tischer, B. K., Vautherot, J. F., and Osterrieder, N. (2002). Characterization of Marek's disease virus serotype 1 (MDV-1) deletion mutants that lack UL46 to UL49 genes: MDV-1 UL49, encoding VP22, is indispensable for virus growth. J. Virol. 76, 1959-1970. doi: 10.1128/jvi.76.4.1959-1970.2002

Drozdetskiy, A., Cole, C., Procter, J., and Barton, G. J. (2015). JPred4: a protein secondary structure prediction server. Nucleic Acids Res. 43, W389-W394.

Duffy, C., Lavail, J. H., Tauscher, A. N., Wills, E. G., Blaho, J. A., and Baines, J. D. (2006). Characterization of a UL49-null mutant: VP22 of herpes simplex virus type 1 facilitates viral spread in cultured cells and the mouse cornea. J. Virol. 80, 8664-8675. doi: 10.1128/jvi.00498-06

Duffy, C., Mbong, E. F., and Baines, J. D. (2009). VP22 of herpes simplex virus 1 promotes protein synthesis at late times in infection and accumulation of a subset of viral mRNAs at early times in infection. J. Virol. 83, 1009-1017. doi: 10.1128 /jvi.02245-07

Ebert, K., Depledge, D. P., Breuer, J., Harman, L., and Elliott, G. (2013). Mode of virus rescue determines the acquisition of VHS mutations in VP22-negative herpes simplex virus 1. J. Virol. 87, 10389-10393. doi: 10.1128/jvi.01654-13

Elliott, G., Hafezi, W., Whiteley, A., and Bernard, E. (2005). Deletion of the herpes simplex virus VP22-encoding gene (UL49) alters the expression, localization, and virion incorporation of ICP0. J. Virol. 79, 9735-9745. doi: 10.1128/jvi.79. 15.9735-9745.2005

Elliott, G., Mouzakitis, G., and O'Hare, P. (1995). VP16 interacts via its activation domain with VP22, a tegument protein of herpes simplex virus, and is relocated to a novel macromolecular assembly in coexpressing cells. J. Virol. 69, 79327941. doi: 10.1128 /jvi.69.12.7932-7941.1995

Elliott, G., and O'Hare, P. (1998). Herpes simplex virus type 1 tegument protein VP22 induces the stabilization and hyperacetylation of microtubules. J. Virol. 72, 6448-6455. doi: 10.1128/jvi.72.8.6448-6455.1998

Elliott, G., and O'Hare, P. (1999). Live-cell analysis of a green fluorescent proteintagged herpes simplex virus infection. J. Virol. 73, 4110-4119. doi: 10.1128/jvi. 73.5.4110-4119.1999

Elliott, G., and O'Hare, P. (2000). Cytoplasm-to-nucleus translocation of a herpesvirus tegument protein during cell division. J. Virol. 74, 2131-2141. doi: 10.1128/jvi.74.5.2131-2141.2000

Elliott, G., O'Reilly, D., and O'Hare, P. (1996). Phosphorylation of the herpes simplex virus type 1 tegument protein VP22. Virology 226, 140-145. doi: 10.1006/viro.1996.0638

Elliott, G., Pheasant, K., Ebert-Keel, K., Stylianou, J., Franklyn, A., and Jones, J. (2018). Multiple posttranscriptional strategies to regulate the herpes simplex virus 1 vhs Endoribonuclease. J. Virol. 92:e00818-18.

Elliott, G. D., and Meredith, D. M. (1992). The herpes simplex virus type 1 tegument protein VP22 is encoded by gene UL49. J. Gen. Virol. 73(Pt 3), 723-726. doi: 10.1099/0022-1317-73-3-723

Farnsworth, A., Wisner, T. W., and Johnson, D. C. (2007). Cytoplasmic residues of herpes simplex virus glycoprotein $\mathrm{gE}$ required for secondary envelopment and binding of tegument proteins VP22 and UL11 to gE and gD. J. Virol. 81, 319-331. doi: 10.1128/jvi.01842-06

Flemington, E. K. (2001). Herpesvirus lytic replication and the cell cycle: arresting new developments. J. Virol. 75, 4475-4481. doi: 10.1128/jvi.75.10.4475-4481. 2001
Foulon, T. (1992). [Herpesviridae: classification and structure in 1991]. Comp. Immunol. Microbiol. Infect. Dis. 15, 13-29. doi: 10.1016/0147-9571(92)90098-c

Fuchs, W., Klupp, B. G., Granzow, H., Hengartner, C., Brack, A., Mundt, A., et al. (2002). Physical interaction between envelope glycoproteins $\mathrm{E}$ and $\mathrm{M}$ of pseudorabies virus and the major tegument protein UL49. J. Virol. 76, 8208-8217. doi: 10.1128/jvi.76.16.8208-8217.2002

Geiss, B. J., Tavis, J. E., Metzger, L. M., Leib, D. A., and Morrison, L. A. (2001). Temporal regulation of herpes simplex virus type 2 VP22 expression and phosphorylation. J. Virol. 75, 10721-10729. doi: 10.1128/jvi.75.22.10721-10729. 2001

Granzow, H., Klupp, B. G., and Mettenleiter, T. C. (2005). Entry of pseudorabies virus: an immunogold-labeling study. J. Virol. 79, 3200-3205. doi: 10.1128/jvi. 79.5.3200-3205.2005

Grauwet, K., Vitale, M., De Pelsmaeker, S., Jacob, T., Laval, K., Moretta, L., et al. (2016). Pseudorabies Virus US3 Protein Kinase Protects Infected Cells from NK Cell-Mediated Lysis via Increased Binding of the Inhibitory NK Cell Receptor CD300a. J. Virol. 90, 1522-1533. doi: 10.1128/jvi.02902-15

Gruffat, H., Marchione, R., and Manet, E. (2016). Herpesvirus late gene expression: a viral-specific pre-initiation complex is key. Front. Microbiol. 7:869. doi: 10. 3389/fmicb.2016.00869

Hafezi, W., Bernard, E., Cook, R., and Elliott, G. (2005). Herpes simplex virus tegument protein VP22 contains an internal VP16 interaction domain and a C-terminal domain that are both required for VP22 assembly into the virus particle. J. Virol. 79, 13082-13093. doi: 10.1128/jvi.79.20.13082-13093.2005

Harms, J. S., Ren, X., Oliveira, S. C., and Splitter, G. A. (2000). Distinctions between bovine herpesvirus 1 and herpes simplex virus type 1 VP22 tegument protein subcellular associations. J. Virol. 74, 3301-3312. doi: 10.1128/jvi.74.7.33013312.2000

He, T., Wang, M., Cheng, A., Yang, Q., Wu, Y., Jia, R., et al. (2020). Host shutoff activity of VHS and SOX-like proteins: role in viral survival and immune evasion. Virol. J. 17:68.

Heine, J. W., Honess, R. W., Cassai, E., and Roizman, B. (1974). Proteins specified by herpes simplex virus. XII. The virion polypeptides of type 1 strains. J. Virol. 14, 640-651. doi: 10.1128/jvi.14.3.640-651.1974

Heming, J. D., Conway, J. F., and Homa, F. L. (2017). Herpesvirus Capsid Assembly and DNA Packaging. Adv. Anat. Embryol. Cell Biol. 223, 119-142. doi: 10.1007/ 978-3-319-53168-7_6

Hew, K., Dahlroth, S. L., Pan, L. X., Cornvik, T., and Nordlund, P. (2015). VP22 core domain from Herpes simplex virus 1 reveals a surprising structural conservation in both the Alpha- and Gammaherpesvirinae subfamilies. J. Gen. Virol. 96, 1436-1445. doi: 10.1099/vir.0.000078

Huang, J., You, H., Su, C., Li, Y., Chen, S., and Zheng, C. (2018). Herpes simplex virus 1 tegument protein VP22 Abrogates cGAS/STING-Mediated Antiviral Innate Immunity. J. Virol. 92:e00841-18.

Hutchinson, I., Whiteley, A., Browne, H., and Elliott, G. (2002). Sequential localization of two herpes simplex virus tegument proteins to punctate nuclear dots adjacent to ICP0 domains. J. Virol. 76, 10365-10373. doi: 10.1128/jvi.76. 20.10365-10373.2002

Ingvarsdottir, K., and Blaho, J. A. (2010). Association of the herpes simplex virus major tegument structural protein VP22 with chromatin. Biochim. Biophys. Acta 1799, 200-206. doi: 10.1016/j.bbagrm.2009.08.002

Jarosinski, K. W., Arndt, S., Kaufer, B. B., and Osterrieder, N. (2012). Fluorescently tagged pUL47 of Marek's disease virus reveals differential tissue expression of the tegument protein in vivo. J. Virol. 86, 2428-2436. doi: 10.1128/jvi.06719-11

Johnson, D. C., and Baines, J. D. (2011). Herpesviruses remodel host membranes for virus egress. Nat. Rev. Microbiol. 9, 382-394. doi: 10.1038/nrmicro2559

Kalthoff, D., Granzow, H., Trapp, S., and Beer, M. (2008). The UL49 gene product of BoHV-1: a major factor in efficient cell-to-cell spread. J. Gen. Virol. 89, 2269-2274. doi: 10.1099/vir.0.2008/000208-0

Kelly, B. J., Fraefel, C., Cunningham, A. L., and Diefenbach, R. J. (2009). Functional roles of the tegument proteins of herpes simplex virus type 1. Virus Res. 145, 173-186. doi: 10.1016/j.virusres.2009.07.007

Kennedy, P. G. E., Grinfeld, E., Craigon, M., Vierlinger, K., Roy, D., Forster, T., et al. (2005). Transcriptomal analysis of varicella-zoster virus infection using long oligonucleotide-based microarrays. J. Gen. Virol. 86, 2673-2684. doi: 10.1099/vir.0.80946-0

Klupp, B. G., Hellberg, T., Granzow, H., Franzke, K., Dominguez Gonzalez, B., Goodchild, R. E., et al. (2017). Integrity of the Linker of Nucleoskeleton 
and cytoskeleton is required for efficient Herpesvirus Nuclear Egress. J. Virol. 91:e00330-17.

Knopf, K. W., and Kaerner, H. C. (1980). Virus-specific basic phosphoproteins associated with herpes simplex virus type a (HSV-1) particles and the chromatin of HSV-1-infected cells. J. Gen. Virol. 46, 405-414. doi: 10.1099/0022-1317-462-405

Kotsakis, A., Pomeranz, L. E., Blouin, A., and Blaho, J. A. (2001). Microtubule reorganization during herpes simplex virus type 1 infection facilitates the nuclear localization of VP22, a major virion tegument protein. J. Virol. 75, 8697-8711. doi: 10.1128/jvi.75.18.8697-8711.2001

Kramer, T., and Enquist, L. W. (2013). Directional spread of alphaherpesviruses in the nervous system. Viruses 5, 678-707. doi: 10.3390/v5020678

Kukhanova, M. K., Korovina, A. N., and Kochetkov, S. N. (2014). Human herpes simplex virus: life cycle and development of inhibitors. Biochemistry 79, 16351652. doi: $10.1134 / \mathrm{s} 0006297914130124$

Labiuk, S. L., Lobanov, V., Lawman, Z., Snider, M., Babiuk, L. A., and van Drunen Littel-van den Hurk, S. (2010). Bovine herpesvirus-1 US3 protein kinase: critical residues and involvement in the phosphorylation of VP22. J. Gen. Virol. 91, 1117-1126. doi: 10.1099/vir.0.016600-0

Lebrun, M., Lambert, J., Riva, L., Thelen, N., Rambout, X., Blondeau, C., et al. (2018). Varicella-Zoster Virus ORF9p binding to cellular adaptor protein complex 1 is important for viral infectivity. J. Virol. 92:e00295-18.

Leslie, J., Rixon, F. J., and McLauchlan, J. (1996). Overexpression of the herpes simplex virus type 1 tegument protein VP22 increases its incorporation into virus particles. Virology 220, 60-68. doi: 10.1006/viro.1996.0286

Liang, M. H., Geisbert, T., Yao, Y., Hinrichs, S. H., and Giam, C. Z. (2002). Human T-lymphotropic virus type 1 oncoprotein tax promotes S-phase entry but blocks mitosis. J. Virol. 76, 4022-4033. doi: 10.1128/jvi.76.8.4022-4033.2002

Liang, X., Chow, B., Li, Y., Raggo, C., Yoo, D., Attah-Poku, S., et al. (1995). Characterization of bovine herpesvirus 1 UL49 homolog gene and product: bovine herpesvirus 1 UL49 homolog is dispensable for virus growth. J. Virol. 69, 3863-3867. doi: 10.1128/jvi.69.6.3863-3867.1995

Liashkovich, I., Hafezi, W., Kuhn, J. M., Oberleithner, H., and Shahin, V. (2011). Nuclear delivery mechanism of herpes simplex virus type 1 genome. J. Mol. Recognit. 24, 414-421. doi: 10.1002/jmr.1120

Liu, J., Gallo, R. M., Duffy, C., and Brutkiewicz, R. R. (2016). A VP22-Null HSV-1 is impaired in inhibiting CD1d-mediated antigen presentation. Viral Immunol. 29, 409-416. doi: 10.1089/vim.2015.0145

Liu, X., Main, D., Ma, Y., and He, B. (2018). Herpes Simplex Virus 1 Inhibits TANK-Binding Kinase 1 through Formation of the Us11-Hsp90 Complex. J. Virol. 92:e00402-18.

Lobanov, V. A., Zheng, C., Babiuk, L. A., and van Drunen Littel-van den Hurk, S. (2010). Intracellular trafficking of VP22 in bovine herpesvirus-1 infected cells. Virology 396, 189-202. doi: 10.1016/j.virol.2009.10.022

López, M. R., Schlegel, E. F., Wintersteller, S., and Blaho, J. A. (2008). The major tegument structural protein VP22 targets areas of dispersed nucleolin and marginalized chromatin during productive herpes simplex virus 1 infection. Virus Res. 136, 175-188. doi: 10.1016/j.virusres.2008.05.010

Loret, S., Guay, G., and Lippé, R. (2008). Comprehensive characterization of extracellular herpes simplex virus type 1 virions. J. Virol. 82, 8605-8618. doi: 10.1128/jvi.00904-08

Ma, D. X., Yu, X. P., Zhang, X. M., Zhou, Y. B., Li, Y., Jia, J. H., et al. (2005). [VP22 enhances the immunological activity of human cytomegalovirus pp65 DNA vaccine: experimental study with mice]. Zhonghua Yi Xue Za Zhi 85, 1049-1052.

Maringer, K., and Elliott, G. (2010). Recruitment of herpes simplex virus type 1 immediate-early protein ICP0 to the virus particle. J. Virol. 84, 4682-4696. doi: 10.1128/jvi.00126-10

Maringer, K., Stylianou, J., and Elliott, G. (2012). A network of protein interactions around the herpes simplex virus tegument protein VP22. J. Virol. 86, 1297112982. doi: 10.1128 /jvi.01913-12

Maruzuru, Y., Ichinohe, T., Sato, R., Miyake, K., Okano, T., Suzuki, T., et al. (2018). Herpes simplex virus 1 VP22 Inhibits AIM2-dependent inflammasome activation to enable efficient viral replication. Cell Host Microbe 23, 254-265.e7. doi: 10.1016/j.chom.2017.12.014

Maurer, U. E., Sodeik, B., and Grünewald, K. (2008). Native 3D intermediates of membrane fusion in herpes simplex virus 1 entry. Proc. Natl. Acad. Sci. U.S.A. 105, 10559-10564. doi: 10.1073/pnas.0801674105
Mbong, E. F., Woodley, L., Dunkerley, E., Schrimpf, J. E., Morrison, L. A., and Duffy, C. (2012). Deletion of the herpes simplex virus 1 UL49 gene results in mRNA and protein translation defects that are complemented by secondary mutations in UL41. J. Virol. 86, 12351-12361. doi: 10.1128/jvi.01975-12

Mercer, J., Schelhaas, M., and Helenius, A. (2010). Virus entry by endocytosis. Annu. Rev. Biochem. 79, 803-833. doi: 10.1146/annurev-biochem-060208104626

Meredith, D. M., Lindsay, J. A., Halliburton, I. W., and Whittaker, G. R. (1991). Post-translational modification of the tegument proteins (VP13 and VP14) of herpes simplex virus type 1 by glycosylation and phosphorylation. J. Gen. Virol. 72(Pt 11), 2771-2775. doi: 10.1099/0022-1317-72-11-2771

Metrick, C. M., Koenigsberg, A. L., and Heldwein, E. E. (2020). Conserved outer tegument component UL11 from herpes simplex virus 1 is an intrinsically disordered, RNA-binding protein. mBio 11:e00810-20.

Mettenleiter, T. C. (2002). Herpesvirus assembly and egress. J. Virol. 76, 1537-1547. doi: 10.1128/jvi.76.4.1537-1547.2002

Michael, K., Klupp, B. G., Karger, A., and Mettenleiter, T. C. (2007). Efficient incorporation of tegument proteins pUL46, pUL49, and pUS3 into pseudorabies virus particles depends on the presence of pUL21. J. Virol. 81, 1048-1051. doi: 10.1128/jvi.01801-06

Mohni, K. N., Dee, A. R., Smith, S., Schumacher, A. J., and Weller, S. K. (2013). Efficient herpes simplex virus 1 replication requires cellular ATR pathway proteins. J. Virol. 87, 531-542. doi: 10.1128/jvi.02504-12

Morrison, E. E., Wang, Y. F., and Meredith, D. M. (1998). Phosphorylation of structural components promotes dissociation of the herpes simplex virus type 1 tegument. J. Virol. 72, 7108-7114. doi: 10.1128/jvi.72.9.7108-7114.1998

Mouzakitis, G., McLauchlan, J., Barreca, C., Kueltzo, L., and O’Hare, P. (2005). Characterization of VP22 in herpes simplex virus-infected cells. J. Virol. 79, 12185-12198. doi: 10.1128/jvi.79.19.12185-12198.2005

Nishi, K., and Saigo, K. (2007). Cellular internalization of green fluorescent protein fused with herpes simplex virus protein VP22 via a lipid raft-mediated endocytic pathway independent of caveolae and Rho family GTPases but dependent on dynamin and Arf6. J. Biol. Chem. 282, 27503-27517. doi: 10. 1074/jbc.m703810200

Okada, A., Izume, S., Ohya, K., and Fukushi, H. (2015). Equine herpesvirus type 1 tegument protein VP22 is not essential for pathogenicity in a hamster model, but is required for efficient viral growth in cultured cells. J. Vet. Med. Sci. 77, 1293-1297. doi: 10.1292/jvms.14-0648

Okada, A., Kodaira, A., Hanyu, S., Izume, S., Ohya, K., and Fukushi, H. (2014). Intracellular localization of Equine herpesvirus type 1 tegument protein VP22. Virus Res. 192, 103-113. doi: 10.1016/j.virusres.2014.08.006

Okada, A., Suganuma, S., Badr, Y., Omatsu, T., Mizutani, T., Ohya, K., et al. (2018). Decreased expression of the immediate early protein, ICP4, by deletion of the tegument protein VP22 of equine herpesvirus type 1. J. Vet. Med. Sci. 80, 311-315. doi: 10.1292/jvms. 17-0380

Oral, O., Akkoc, Y., Bayraktar, O., and Gozuacik, D. (2016). Physiological and pathological significance of the molecular cross-talk between autophagy and apoptosis. Histol. Histopathol. 31, 479-498.

O’Regan, K. J., Brignati, M. J., Murphy, M. A., Bucks, M. A., and Courtney, R. J. (2010). Virion incorporation of the herpes simplex virus type 1 tegument protein VP22 is facilitated by trans-Golgi network localization and is independent of interaction with glycoprotein E. Virology 405, 176-192. doi: 10.1016/j.virol.2010.06.007

O’Regan, K. J., Bucks, M. A., Murphy, M. A., Wills, J. W., and Courtney, R. J. (2007a). A conserved region of the herpes simplex virus type 1 tegument protein VP22 facilitates interaction with the cytoplasmic tail of glycoprotein E (gE). Virology 358, 192-200. doi: 10.1016/j.virol.2006.08.024

O'Regan, K. J., Murphy, M. A., Bucks, M. A., Wills, J. W., and Courtney, R. J. (2007b). Incorporation of the herpes simplex virus type 1 tegument protein VP22 into the virus particle is independent of interaction with VP16. Virology 369, 263-280. doi: 10.1016/j.virol.2007.07.020

Orzalli, M. H., Broekema, N. M., Diner, B. A., Hancks, D. C., Elde, N. C., Cristea, I. M., et al. (2015). cGAS-mediated stabilization of IFI16 promotes innate signaling during herpes simplex virus infection. Proc. Natl. Acad. Sci. U.S.A. 112, E1773-E1781.

Owen, D. J., Crump, C. M., and Graham, S. C. (2015). Tegument assembly and secondary envelopment of Alphaherpesviruses. Viruses 7, 5084-5114. doi: 10. $3390 / \mathrm{v} 7092861$ 
Pannhorst, K., Wei, H., Yezid, H., He, J., and Chowdhury, S. I. (2018). Bovine Herpesvirus $1 \mathrm{U}(\mathrm{L}) 49.5$ Interacts with gM and VP22 To ensure virus cell-toCell spread and virion incorporation: novel role for VP22 in gM-Independent U(L)49.5 Virion Incorporation. J. Virol. 92:e00240-18.

Pheasant, K., Möller-Levet, C. S., Jones, J., Depledge, D., Breuer, J., and Elliott, G. (2018). Nuclear-cytoplasmic compartmentalization of the herpes simplex virus 1 infected cell transcriptome is co-ordinated by the viral endoribonuclease vhs and cofactors to facilitate the translation of late proteins. PLoS Pathog. 14:e1007331. doi: 10.1371/journal.ppat.1007331

Pinard, M. F., Simard, R., and Bibor-Hardy, V. (1987). DNA-binding proteins of herpes simplex virus type 1-infected BHK cell nuclear matrices. J. Gen. Virol. 68(Pt 3), 727-735. doi: 10.1099/0022-1317-68-3-727

Pomeranz, L. E., and Blaho, J. A. (1999). Modified VP22 localizes to the cell nucleus during synchronized herpes simplex virus type 1 infection. J. Virol. 73, 6769-6781. doi: 10.1128/jvi.73.8.6769-6781.1999

Pomeranz, L. E., and Blaho, J. A. (2000). Assembly of infectious Herpes simplex virus type 1 virions in the absence of full-length VP22. J. Virol. 74, 10041-10054. doi: 10.1128/jvi.74.21.10041-10054.2000

Qiu, Z., Zhu, J., Harms, J. S., Friedrichsen, J., and Splitter, G. A. (2005). Bovine herpesvirus VP22 induces apoptosis in neuroblastoma cells by upregulating the expression ratio of Bax to Bcl-2. Hum. Gene Ther. 16, 101-108. doi: 10.1089/ hum.2005.16.101

Ren, X., Harms, J. S., and Splitter, G. A. (2001). Bovine herpesvirus 1 tegument protein VP22 interacts with histones, and the carboxyl terminus of VP22 is required for nuclear localization. J. Virol. 75, 8251-8258. doi: 10.1128/jvi.75. $17.8251-8258.2001$

Riva, L., Thiry, M., Bontems, S., Joris, A., Piette, J., Lebrun, M., et al. (2013). ORF9p phosphorylation by ORF47p is crucial for the formation and egress of varicella-zoster virus viral particles. J. Virol. 87, 2868-2881. doi: 10.1128/jvi. 02757-12

Roizman, B., Carmichael, L. E., Deinhardt, F., de-The, G., Nahmias, A. J., Plowright, W., et al. (1981). Herpesviridae. Definition, provisional nomenclature, and taxonomy. The Herpesvirus Study Group, the International Committee on Taxonomy of Viruses. Intervirology 16, 201-217.

Roizman, B., and Sears, A. E. (1996). "Herpes simplex viruses and their replication," in Fields Virology, 3rd Edn, eds B. N. Fields, D. M. Knipe, and P. M. Howley (Philadelphia, PA: Lippincott-Raven), 2231-2296.

Schlegel, E. F., and Blaho, J. A. (2009). A conserved carboxy-terminal domain in the major tegument structural protein VP22 facilitates virion packaging of a chimeric protein during productive herpes simplex virus 1 infection. Virology 387, 449-458. doi: 10.1016/j.virol.2009.02.040

Sciortino, M. T., Taddeo, B., Giuffrè-Cuculletto, M., Medici, M. A., Mastino, A., and Roizman, B. (2007). Replication-competent herpes simplex virus 1 isolates selected from cells transfected with a bacterial artificial chromosome DNA lacking only the UL49 gene vary with respect to the defect in the UL41 gene encoding host shutoff RNase. J. Virol. 81, 10924-10932. doi: 10.1128/jvi.0123907

Sciortino, M. T., Taddeo, B., Poon, A. P., Mastino, A., and Roizman, B. (2002). Of the three tegument proteins that package mRNA in herpes simplex virions, one (VP22) transports the mRNA to uninfected cells for expression prior to viral infection. Proc. Natl. Acad. Sci. U.S.A. 99, 8318-8323. doi: 10.1073/pnas. 122231699

Song, M. J., Hwang, S., Wong, W. H., Wu, T. T., Lee, S., Liao, H. I., et al. (2005). Identification of viral genes essential for replication of murine gammaherpesvirus 68 using signature-tagged mutagenesis. Proc. Natl. Acad. Sci. U.S.A. 102, 3805-3810. doi: 10.1073/pnas.0404521102

Starkey, J. L., Han, J., Chadha, P., Marsh, J. A., and Wills, J. W. (2014). Elucidation of the block to herpes simplex virus egress in the absence of tegument protein UL16 reveals a novel interaction with VP22. J. Virol. 88, 110-119. doi: 10.1128/ jvi.02555-13

Stylianou, J., Maringer, K., Cook, R., Bernard, E., and Elliott, G. (2009). Virion incorporation of the herpes simplex virus type 1 tegument protein VP22 occurs via glycoprotein E-specific recruitment to the late secretory pathway. J. Virol. 83, 5204-5218. doi: 10.1128/jvi.00069-09

Su, C., and Zheng, C. (2017). Herpes Simplex Virus 1 Abrogates the cGAS/STINGMediated Cytosolic DNA-Sensing Pathway via Its Virion Host Shutoff Protein, UL41. J. Virol. 91:e2414-16.
Sugimoto, K., Uema, M., Sagara, H., Tanaka, M., Sata, T., Hashimoto, Y., et al. (2008). Simultaneous tracking of capsid, tegument, and envelope protein localization in living cells infected with triply fluorescent herpes simplex virus 1. J. Virol. 82, 5198-5211. doi: 10.1128/jvi.02681-07

Sun, L., Wu, J., Du, F., Chen, X., and Chen, Z. J. (2013). Cyclic GMP-AMP synthase is a cytosolic DNA sensor that activates the type I interferon pathway. Science 339, 786-791. doi: 10.1126/science. 1232458

Taddeo, B., Sciortino, M. T., Zhang, W., and Roizman, B. (2007). Interaction of herpes simplex virus RNase with VP16 and VP22 is required for the accumulation of the protein but not for accumulation of mRNA. Proc. Natl. Acad. Sci. U.S.A. 104, 12163-12168. doi: 10.1073/pnas.0705245104

Tanaka, M., Kato, A., Satoh, Y., Ide, T., Sagou, K., Kimura, K., et al. (2012). Herpes simplex virus 1 VP22 regulates translocation of multiple viral and cellular proteins and promotes neurovirulence. J. Virol. 86, 5264-5277. doi: 10.1128/ jvi.06913-11

Timney, B. L., Raveh, B., Mironska, R., Trivedi, J. M., Kim, S. J., Russel, D., et al. (2016). Simple rules for passive diffusion through the nuclear pore complex. J. Cell Biol. 215, 57-76. doi: 10.1083/jcb.201601004

Tobler, K., Senn, C., Schraner, E. M., Ackermann, M., Fraefel, C., and Wild, P. (2019). The herpes simplex virus 1 Us3 kinase is involved in assembly of membranes needed for viral envelopment and in distribution of glycoprotein K. F1000Res. 8:727. doi: 10.12688/f1000research.19194.1

Trapp-Fragnet, L., Bencherit, D., Chabanne-Vautherot, D., Le Vern, Y., Remy, S., Boutet-Robinet, E., et al. (2014). Cell cycle modulation by Marek's disease virus: the tegument protein VP22 triggers S-phase arrest and DNA damage in proliferating cells. PLoS One 9:e100004. doi: 10.1371/journal.pone.0100004

Trapp-Fragnet, L., Courvoisier, K., Remy, S., Pape, G. L., Loustalot, F., and Denesvre, C. (2019). Identification of Marek's Disease Virus VP22 tegument protein domains essential for virus cell-to-cell spread, nuclear localization, histone association and cell-cycle arrest. Viruses 11:537. doi: 10.3390/ v11060537

Van den Broeke, C., Deruelle, M., Nauwynck, H. J., Coller, K. E., Smith, G. A., Van Doorsselaere, J., et al. (2009). The kinase activity of pseudorabies virus US3 is required for modulation of the actin cytoskeleton. Virology 385, 155-160. doi: 10.1016/j.virol.2008.11.050

van Leeuwen, H., Elliott, G., and O'Hare, P. (2002). Evidence of a role for nonmuscle myosin II in herpes simplex virus type 1 egress. J. Virol. 76, 3471-3481. doi: 10.1128/jvi.76.7.3471-3481.2002

van Leeuwen, H., Okuwaki, M., Hong, R., Chakravarti, D., Nagata, K., and O'Hare, P. (2003). Herpes simplex virus type 1 tegument protein VP22 interacts with TAF-I proteins and inhibits nucleosome assembly but not regulation of histone acetylation by INHAT. J. Gen. Virol. 84, 2501-2510. doi: 10.1099/vir.0.19326-0

Vicente-Manzanares, M., Ma, X., Adelstein, R. S., and Horwitz, A. R. (2009). Nonmuscle myosin II takes centre stage in cell adhesion and migration. Nat. Rev. Mol. Cell Biol. 10, 778-790.

Wang, Y., Wang, R., Li, F., Wang, Y., Zhang, Z., Wang, Q., et al. (2018). Heat-shock protein 90alpha is involved in maintaining the stability of VP16 and VP16mediated transactivation of alpha genes from herpes simplex virus-1. Mol. Med. 24:65.

Wang, Z., Wang, Y., Wang, S., Meng, X., Song, F., Huo, W., et al. (2018). Coxsackievirus A6 induces cell cycle arrest in G0/G1 phase for viral production. Front. Cell. Infect. Microbiol. 8:279. doi: 10.3389/fcimb.2018.00279

Wu, Y., Cheng, A., Wang, M., Yang, Q., Zhu, D., Jia, R., et al. (2012). Complete genomic sequence of Chinese virulent duck enteritis virus. J. Virol. 86:5965.

Xie, Y., Wu, L., Wang, M., Cheng, A., Yang, Q., Wu, Y., et al. (2019). Alpha-Herpesvirus Thymidine kinase genes mediate viral virulence and are potential therapeutic targets. Front. Microbiol. 10:941. doi: 10.3389/fmicb.2019. 00941

Yang, L., Wang, M., Cheng, A., Yang, Q., Wu, Y., Jia, R., et al. (2019). Innate immune evasion of Alphaherpesvirus tegument proteins. Front. Immunol. 10:2196. doi: 10.3389/fimmu.2019.02196

You, H., Zheng, S., Huang, Z., Lin, Y., Shen, Q., and Zheng, C. (2019). Herpes simplex virus 1 tegument protein UL46 Inhibits TANK-Binding Kinase 1Mediated Signaling. mBio 10:e00919-19.

You, Y., Cheng, A. C., Wang, M. S., Jia, R. Y., Sun, K. F., Yang, Q., et al. (2017). The suppression of apoptosis by alpha-herpesvirus. Cell Death Dis. 8:e2749. 
Yu, J., Zhang, L., Ren, P., Zhong, T., Li, Z., Wang, Z., et al. (2015). Enterovirus 71 mediates cell cycle arrest in S phase through non-structural protein 3D. Cell Cycle 14, 425-436.

Yu, X., Wang, Y., Xia, Y., Zhang, L., Yang, Q., and Lei, J. (2016). A DNA vaccine encoding VP22 of herpes simplex virus type I (HSV-1) and OprF confers enhanced protection from Pseudomonas aeruginosa in mice. Vaccine 34, 4399-4405.

Yu, X., Xiao, S., Jiang, Y., Fang, L., Chen, H., and Jin, M. (2012). A DNA vaccine encoding the FMDV capsid precursor polypeptide P1 and the enhancing effect of bovine herpesvirus 1 VP22 protein as molecular adjuvant. Acta Virol. 56, 111-117.

Yu, X., Xu, Z., Lei, J., Li, T., and Wang, Y. (2015). VP22 mediates intercellular trafficking and enhances the in vitro antitumor activity of PTEN. Mol. Med. Rep. 12, 1286-1290.

Zandi, F., Eslami, N., Torkashvand, F., Fayaz, A., Khalaj, V., and Vaziri, B. (2013). Expression changes of cytoskeletal associated proteins in proteomic profiling of neuroblastoma cells infected with different strains of rabies virus. J. Med. Virol. 85, 336-347.

Zeev-Ben-Mordehai, T., Hagen, C., and Grunewald, K. (2014). A cool hybrid approach to the herpesvirus 'life' cycle. Curr. Opin. Virol. 5, 42-49.
Zheng, C., Brownlie, R., Babiuk, L. A., and van Drunen Littel-van den Hurk, S. (2005). Characterization of the nuclear localization and nuclear export signals of bovine herpesvirus 1 VP22. J. Virol. 79, 11864-11872.

Zhou, X., Jiang, W., Liu, Z., Liu, S., and Liang, X. (2017). Virus infection and death receptor-mediated apoptosis. Viruses 9:316.

Zhu, J., Qiu, Z., Wiese, C., Ishii, Y., Friedrichsen, J., Rajashekara, G., et al. (2005). Nuclear and mitochondrial localization signals overlap within bovine herpesvirus 1 tegument protein VP22. J. Biol. Chem. 280, 16038-16044.

Conflict of Interest: The authors declare that the research was conducted in the absence of any commercial or financial relationships that could be construed as a potential conflict of interest.

Copyright (C) 2020 Wu, Cheng, Wang, Jia, Yang, Wu, Zhu, Zhao, Chen, Liu, Zhang, Ou, Mao, Gao, Sun, Wen, Liu, Yu, Zhang, Tian, Pan and Chen. This is an open-access article distributed under the terms of the Creative Commons Attribution License (CC BY). The use, distribution or reproduction in other forums is permitted, provided the original author(s) and the copyright owner(s) are credited and that the original publication in this journal is cited, in accordance with accepted academic practice. No use, distribution or reproduction is permitted which does not comply with these terms. 